\title{
100 años de libre determinación de los pueblos. La evolución del principio
}

100 years of self-determination of peoples. The evolution of the principle

Juan Jorge PIERNAS LóPEZ

Profesor Contratado Doctor de Derecho internacional Público

Universidad de Murcia

jjpiernas@um.es

Resumen: El presente artículo tiene por objeto analizar la evolución del principio de libre determinación de los pueblos en los últimos 100 años en Derecho internacional. A tal efecto, el artículo examina los principales trabajos doctrinales y la práctica estatal y de Naciones Unidas. El trabajo concluye que el principio ha pasado por tres etapas fundamentales en las que su contenido ha cambiado y se cuestiona si acontecimientos recientes podrían estar marcando el inicio de una cuarta etapa.

Palabras clave: Libre determinación, Derecho internacional, Pueblos, Evolución, Naciones Unidas, Práctica estatal.
Abstract: This article aims to analyze the evolution of the principle of self-determination of peoples over the past 100 years under International law. To this end, the article examines the main doctrinal works and the State and United Nations practice. The paper concludes that the principle has gone through three fundamental stages where its content has changed and questions whether recent events could be signaling the beginning of a fourth stage.

Keywords: Self-determination, International law, Peoples, Evolution, United Nations, State practice.

Sumario: I. INTRODUCCIÓN. II. PRIMERA ETAPA: LENIN, WILSON Y LA LIGA DE LAS NACIONES. III. SEGUNDA ETAPA: NACIONES UNIDAS Y LA DESCOLONIZACIÓN. IV. TERCERA ETAPA: EL PRINCIPIO DE LIBRE DETERMINACIÓN Y LOS PUEBLOS NO COLONIALES. V. ¿HACIA UNA CUARTA ETAPA BASADA EN EL DERECHO DEMOCRÁTICO DE LOS PUEBLOS NACIONALES A LA INDEPENDENCIA? VI. CONCLUSIONES

\section{INTRODUCCIÓN}

E n marzo de 1916 Vladímir Ilich Lenin publicaba la revolución socialista y el derecho de las naciones a la autodeterminación, donde afirmaba la existencia y desarrollaba el contenido de un derecho de las naciones a la autodeterminación ${ }^{1}$. Hacia la misma fecha, el 27 de mayo de 1916, en un conocido discurso, el Presidente de los Estados Unidos de América, Thomas Woodrow Wilson, afirmaba que cada pueblo tiene el derecho de escoger la

1 LenIN, V. I., Obras Escogidas, Lawrence and Wishart, Londres, 1969, Tomo V (1913-1916), p. 152. 
soberanía bajo la cual ha de vivir, apuntado de este modo la esencia del principio de libre determinación de los pueblos².

Un siglo más tarde, el principio de libre determinación de los pueblos es, según la Corte Internacional de Justicia, «uno de los principios esenciales del derecho internacional contemporáneo» ${ }^{3}$. Este principio aparece recogido en la Carta de las Naciones Unidas (art. 1.2), y mencionado con mayor detalle en la Resolución 1514 (XV) de la Asamblea General de las Naciones Unidas de 14 de diciembre de 1960, que incluye una Declaración sobre la concesión de la independencia a los países y pueblos coloniales, y en los Pactos Internacionales de Derechos Humanos de 1966, que señalan que «Todos los pueblos tienen el derecho de libre determinación. En virtud de este derecho establecen libremente su condición política y proveen asimismo a su desarrollo económico, social y cultural» ${ }^{4}$. El principio figura también en la Declaración relativa a los principios de derecho internacional referentes a las relaciones de amistad y a la cooperación entre los Estados de conformidad con la Carta de las Naciones Unidas incluida en la Resolución 2625 (xXV), de la Asamblea General de las Naciones Unidas, de 24 de octubre de 1970. El principio de libre determinación ha permitido a los pueblos coloniales acceder a su independencia, o bien a su asociación o integración en otros Estados 5 . Fuera del ámbito colonial, este principio ha sido también invocado por pueblos indígenas ${ }^{6}$, y por pueblos no coloniales que viven

2 Discurso del Presidente Wilson ante la primera Asamblea Anual de la Liga para fomentar la Paz, Washington, D. C., 27 de mayo de 1916. En su versión original el Presidente Wilson afirmó «We believe these fundamental things: First, that every people has a right to choose the sovereignty under which they shall live». En el mismo acto se produjo el levantamiento de Pascua irlandés contra la autoridad del Reino Unido.

3 Sentencia de 30 de junio de 1995, Asunto de Timor Oriental (Portugal c. Australia), CIJ Recueil 1995, 102, párrafo 29.

4 Pacto internacional de Derechos civiles y políticos y Pacto internacional de Derechos económicos, sociales y culturales. Adoptados y abiertos a la firma, ratificación y adhesión por la Asamblea General en su Resolución 2200 A (XXI), de 16 de diciembre de 1966, entraron en vigor el 23 de marzo de 1976, véase su artículo común 1.1.

5 Véase a este respecto, e,g., KREIJEN, G., State Failure, Sovereignty And Effectiveness: Legal Lessons from the Decolonization of Sub-Saharan Africa, Martinus Nijhoff Publishers, Leiden-Boston, 2004, especialmente en pp. 127-141.

6 Véase sobre estos pueblos y su derecho a la libre determinación, de contenido distinto, y más reducido que el de los pueblos coloniales, CASTELlino, J., «International Law and Self-determination Peoples, Indigenous Peoples and Minorities», en Walter, C.; Ungern-STERnberG, A. y Abushov, K. (eds.), Self-Determination and Secession in International Law, Oxford University Press, Oxford, 2014; TORRECUADRADA GARCÍA-LOZANO, S., Los pueblos indígenas en el orden internacional, Dykinson, Madrid, 2001; o MeIJKNecht, A., Towards International Personality: The Position of Minorities and Indigenous Peoples in International Law, Antwerpen/Groningen, Intersentia, 2001. 
en el seno de un Estado soberano e independiente ${ }^{7}$, si bien su contenido, como se discutirá infra, es distinto para estos pueblos no coloniales.

El presente trabajo tiene por objeto analizar la evolución del principio de libre determinación de los pueblos en el último siglo ${ }^{8}$, desde las formulaciones iniciales de Lenin y Wilson hasta la actualidad ${ }^{9}$, y precisar cómo se ha transformado su contenido. Con ese fin, el estudio analiza, en primer lugar, los elementos fundamentales del principio de libre determinación, tal y como fue concebido por Lenin, Wilson y durante la vigencia de la Sociedad de Naciones. A continuación, el trabajo analiza la transformación del principio originalmente político en un instrumento jurídico, el vehículo elegido por la comunidad internacional para acabar con la colonización. En tercer lugar se analiza la aplicación del principio de libre determinación de los pueblos fuera del ámbito de la colonización, es decir, a pueblos indígenas y nacionales a partir de la década de los 70 del pasado siglo, y en concreto de la Resolución 2625(XXV) de la Asamblea General de Naciones Unidas. Por último, a la luz de manifestaciones recientes, como las resoluciones adoptadas por el Parlamento de Cataluña en los últimos años respecto de la posibilidad de acceder a la independencia de forma no consensuada con base en el denominado derecho a decidir, el estudio se plantea si puede atisbarse el inicio de una nueva etapa de evolución del principio, basada en el derecho de los pueblos nacionales a optar por la independencia del Estado en el que viven, aún en ausencia de discriminación o persecución por parte del gobierno de dicho Estado.

7 Así, entre otras obras pueden citarse las siguientes MARIÑo MENÉNDEZ, F. M., «Naciones Unidas y el derecho de autodeterminación», en MARIÑo MENÉNDEZ, F. M. (ed.), Balance y perspectivas de Naciones Unidas en el cincuentenario de su creación, Universidad Carlos III de Madrid-BOE, Madrid, p. 105; GUTIÉRREZ EsPADA, C, «El derecho de libre determinación de los pueblos», en Ansuátegui Roig, F.; De Asís Roig, F.,; Rodríguez Uribes, J. M.; Peces-Barba, G. y FerNÁNDEZ García, E. (dirs.), y Iglesias GARZón, A. (coord.), Historia de los derechos fundamentales, vol. 3, tomo 4, Dykinson, Madrid, 2013, pp. 635-685; y GutiÉrrez Espada, C. y Bermejo GARCía, R., «El derecho de libre determinación de los pueblos no coloniales a la luz del Derecho Internacional», en Solozábal, J.J., La autodeterminación a debate, Fundación Pablo Iglesias, Madrid, 2014, pp. 93-118.

8 Para un análisis de la invocación de este principio antes de 1916 véase, e.g., FABRY, M., Recognizing States. International Society and the Establishment of New States Since 1776, Oxford University Press, Oxford-New York 2010, i.e. p. 9: «State recognition can be said to have (a) emerged over two centuries ago as a full-fledged practice in response to the idea of self-determination of peoples and (b) altered with changes in its understanding that occurred since that time».

9 Véase para un análisis desde los orígenes del principio con el principio de las nacionalidades en el siglo XVIII, GUTIÉRREZ ESPADA, C., «El derecho de libre determinación de los pueblos», op. cit. 


\section{Primera etapa: Lenin, Wilson y la Liga de las Naciones}

En marzo de 1916 se publicaba la revolución socialista y el derecho de las naciones a la autodeterminación de Vladímir Ilich Lenin. En opinión de Lenin, $\ll$ El derecho de las naciones a la autodeterminación significa exclusivamente su derecho a la independencia en el sentido político, el derecho a la libre separación política respecto de la nación que la oprime. [...]. De modo que esta reivindicación no equivale en absoluto a la de separación, fragmentación y formación de pequeños Estados. Significa sólo una manifestación consecuente de lucha contra toda opresión nacional» ${ }^{10}$. Poco después, el 27 de mayo de 1916, en un conocido discurso, el Presidente de los Estados Unidos de América, Thomas Woodrow Wilson, esbozaba la esencia de lo que hoy conocemos como principio de libre determinación de los pueblos en los siguientes términos «Nosotros creemos en estas cosas fundamentales: Primero, que cada pueblo tiene el derecho de escoger la soberanía bajo la cual ha de vivir» ${ }^{11}$. Lenin y Wilson llevaron el principio de la libre determinación de los pueblos al ámbito de las relaciones y la política internacional. Sin embargo, los orígenes de este principio suelen situarse en diversos documentos de los siglos XVII y XVIII, en concreto en el «Bill of Rights» de 1669, el «Habeas Corpus Act» de 1679, la «Virginia Bill of Rights», la Declaración de Independencia de los Estados Unidos de América de 1776, la Constitución americana de 1787 y la Declaración de Derechos del Hombre y del Ciudadano de $1789^{12}$.

En efecto, particularmente las revoluciones americana y francesa contribuyeron, por distintas razones, al nacimiento del principio de autodeterminación. La Declaración de Independencia de los Estados Unidos de América, de 4 de julio de 1776, hace referencias a razones de necesidad y derecho natural al afirmar que «Cuando en el curso de los acontecimientos humanos se hace necesario para un pueblo disolver los vínculos políticos que lo han ligado a otro y tomar entre las naciones de la tierra el puesto separado e igual a que

10 Lenin, V.I., Obras Escogidas, Lawrence and Wishart, Londres, 1969, Tomo V (1913-1916), p. 152.

11 Discurso del Presidente Wilson ante la primera Asamblea Anual de la Liga para fomentar la Paz, Washington, D. C., 27 de mayo de 1916. En su versión original el Presidente Wilson afirmó «We believe these fundamental things: First, that every people has a right to choose the sovereignty under which they shall live».

12 Véase a este respecto, por ejemplo, Seara Vázquez, M., Derecho Internacional Público, Porrúa, México DF, 203 [20ª ed.], p. 81. 
las leyes de la naturaleza y el Dios de esa naturaleza le dan derecho, un justo respeto al juicio de la humanidad exige que declare las causas que lo impulsan a la separación.»

Por su parte, la revolución francesa rechazaba la autoridad del monarca por encima de la de la nación, expresada por el pueblo mediante plebiscito. A este respecto, la Declaración de Derechos del Hombre y del Ciudadano de 1789 subrayaba que «La fuente de toda soberanía reside esencialmente en la Nación; ningún individuo ni ninguna corporación pueden ser revestidos de autoridad alguna que no emane directamente de ella». La revolución francesa estaba notablemente influenciada a este respecto por las ideas de Rosseau y Locke respecto del contrato social, y de la necesidad de que el gobierno fuera representativo de la voluntad del pueblo. No obstante, como ha matizado RAIC, tanto la revolución francesa como la americana estaban basadas en la ilustración y en las ideas del liberalismo y del individualismo, más que en la colectividad, por lo que sería un error equiparar la noción individualista de libre determinación de dichas revoluciones con la noción moderna del principio que hace referencia claramente a un derecho de ciertos colectivos ${ }^{13}$.

Por otro lado, el principio de libre determinación de los pueblos defendido por los revolucionarios franceses, e incluido en el Título XIII del proyecto constitucional de 1793, fue inicialmente concebido para justificar la anexión a Francia de territorios pertenecientes a otros soberanos si la población de dichos territorios así lo expresaba mediante plebiscito, plebiscito que sin embargo sólo se consideraba válido si el resultado era partidario de la anexión ${ }^{14}$. No obstante, a pesar de esta utilización inicial, no se debe ignorar la gran contribución que para el desarrollo posterior del principio tuvo la relación entre voluntad popular y soberanía introducida por la revolución francesa. A este respecto, la revolución francesa tuvo una gran influencia en la expansión del nacionalismo y del conocido como principio de las nacionalidades, según el cual toda nación, si es que quiere ejercer de manera efectiva su soberanía, debe convertirse en Estado. El principio de las nacionalidades, al que también se referiría Rousseau, lleva pues al plano colectivo, al de las colectividades, el derecho individual a la libre determi-

\footnotetext{
13 RaIC, D., Statehood and the Law of Self-Determination, Martinus Nijhoff Publishers, Leiden, Boston, 2002, p. 175.

14 CASSESE, A., Self-determination of peoples. A legal reappraisal, op. cit., pp. 12-13.
} 
nación que habían defendido los revolucionarios franceses y americanos en el siglo XVIII ${ }^{15}$.

Con base en este principio ${ }^{16}$, durante el siglo XIX, tanto en Europa como fuera de ella, números Estados vieron la luz ${ }^{17}$. De esta forma, Bélgica se separó de Holanda en 1831 y Grecia del Imperio Otomano en 1832. Asimismo, Serbia, Rumania y Montenegro fueron también reconocidos como Estados independientes por el Imperio Otomano en 1878. Por último, los dominios de España, Portugal y Gran Bretaña en América alcanzaron la independencia como Estados soberanos durante las primeras décadas del siglo XVIII ${ }^{18}$. Como afirmaba Stuart Mill «it is in general a necessary condition of free institutions that the boundaries of governments should coincide in the main with those of nationalities» ${ }^{19}$. En este marco, Lenin defendía un concepto de libre determinación de los pueblos que permitía a las minorías étnicas, a los grupos nacionales y a las colonias de las potencias europeas la secesión, si así lo decidían los colectivos afectados, o a expresar su deseo de continuar en el seno de un Estado. En los términos del Decreto sobre la Paz, adoptado por el Gobierno soviético en 1917 siguiendo las tesis de Lenin «Si una nación cualquiera es mantenida por la fuerza dentro de los límites de un Estado; si, a pesar del deseo por ella expresado -bien sea a través de la prensa, en las asambleas populares, en las decisiones de los partidos, o por medio de motines e insurrecciones contra la opresión nacional-, no se le concede el derecho a decidir mediante votación libre, después de la retirada completa de las tropas de la nación conquistadora

15 Como ha sintetizado RAIC, «Thus, within the framework of the ideology of nationalism «the conception of individual self-determination as a corollary of democracy» as expressed in the American and the French Revolution shifted, in the words of Carr, «to the conception of nationality as an objective right to independent statehood», RAIC, D., Statehood and the Law of Self-Determination, Martinus Nijhoff Publishers, Leiden, Boston, 2002, p. 176.

16 En este contexto, como afirmaba MazzINI, «The Countries of the People will rise, defined by the voice of the free, upon the ruins of the countries of the Kings and privileged castes. Between these Countries there will be harmony and brotherhood». Véase esta cita de MAZZINI, G., recogida por BEales, D.E.D., Mazzini and the Revolutionary Nationalism, en Thomson, D. (ed.), Political Ideas, Penguin, Londres, 1969, citado por CASSESE, A., Self-determination of peoples. A legal reappraisal, op. cit., p. 13.

17 Véase a este respecto Brownlie, I., 43.1. Brownlie, «An Essay in the History of the Principle of Self-Determination», Grotius Society Papers, 1968, p. 93-94.

18 Sobre el diferente contexto en el que las colonias británicas, españolas y portuguesas véase MEdina Ortega, M., El derecho de secesión en la Unión Europea, Ed. Marcial Pons, Madrid, 2014, pp. 143-147.

19 Cita de Stuart Mill, J., recogida por Hannum, H., «Rethinking Self-Determination», Virginia fournal of International Law, 34, no. 1 (1993), p. 3. 
o que sea en términos generales más poderosa, de decidir sin la menor restricción la cuestión de las formas políticas de su existencia, la incorporación de esta nación al Estado constituye una anexión, es decir, una conquista y un acto de violencia $\gg^{20}$. Este ideal protector de las minorías nacionales y colectivos oprimidos tenía para Lenin un límite: el Socialismo. En caso de conflicto entre el principio de libre determinación y el alcance de los postulados socialistas los segundos debían prevalecer ${ }^{21}$. Lenin, como los líderes de la URSS posteriormente, hizo un uso estratégico, subordinado, del principio respecto de las minorías étnicas y nacionales, si bien el apoyo al principio fue más coherente respecto de la descolonización.

Por su parte, la concepción que el Presidente Wilson tenía del principio de libre determinación de los pueblos experimentó una evolución. En los primeros años, y antes del fin de la Primera Guerra Mundial, libre determinación equivalía para el Presidente Wilson a auto-gobierno democrático, es decir, a la capacidad de las minorías y naciones existentes en Estados ya constituidos a estar representados de forma democrática en la gestión del gobierno de dichos Estados pero sin romper con ellos, algo similar a lo que hoy sería la versión interna del principio de libre determinación. Sin embargo, el Presidente Wilson estuvo de acuerdo con el desmembramiento de los imperios austrohúngaro y otomano con base en las distintas naciones que los componían con posterioridad a la Gran Guerra. La motivación principal para la separación de los grandes imperios en naciones era la de evitar tensiones y con ello nuevas guerras, si bien resultaba también coherente con la idea de que el Gobierno debía ser aceptado de forma democrática por los gobernados. El Presidente Wilson evitó también en su famoso discurso de los catorce puntos referirse de forma explícita a la libre determinación de los pueblos, y más aún equiparar el mismo a secesión incluso violenta, como sí hacía Lenin, si bien hasta seis de los 14 puntos de dicho discurso guardaban relación con el principio de libre determinación ${ }^{22}$. Del mismo modo, un mes después, en su discurso de los cua-

20 ReED, J., Diez días que estremecieron al mundo (Ten days that shook the world), ed. Txalaparta, Tafalla, 2006 (original 1919), p. 118.

21 Como acertadamente cita CASSESE «Which should be put first, the right of nations to self-determination, or socialism? [Lenin] asked rethorically. His answer was «Socialism». CASSESE, A., Self-determination of peoples. A legal reappraisal, op. cit., p. 18.

22 Discurso pronunciado el 8 de enero de 1918 en sesión conjunta del Congreso de los Estados Unidos de América. En concreto, los siguientes puntos están relacionados estrechamente con el principio de libre determinación: Punto V: «Reajuste, absolutamente imparcial, de las reclamaciones coloniales, de tal manera que los intereses de los pueblos merezcan igual consi- 
tro principios, Wilson proclamaba la vigencia del principio de libre determinación al tiempo que cautelosamente señalaba que las aspiraciones nacionales debían recibir la máxima satisfacción pero de forma tal que no se introdujeran nuevos antagonismos o discordias ni perpetuar los ya existentes ${ }^{23}$.

De hecho, en los años que siguieron a la invocación del principio de libre determinación de los pueblos en la esfera internacional, tanto por Lenin como por Wilson, el mismo fue claramente ignorado, habida cuenta de que numerosos territorios cambiaron de soberanía mediante tratados, algunos secretos, en ausencia de plebiscitos ${ }^{24}$, y sin exigir que el nuevo gobierno adoptara una forma democrática coherente con la denominada autodeterminación «interna». En este contexto, la creación de la Sociedad de Naciones por el Tratado de Versalles, el 28 de junio de 1919, tampoco modificó esta situación. El artículo 22 del Pacto de la Sociedad de Naciones establecía un sistema de mandatos mediante el cual las colonias de los perdedores de la Gran Guerra (Alemania y Turquía) se ponían bajo la tutela de algunos Estados (mandatarios) en nombre de la Sociedad de Naciones. No obstante, si bien algunos territorios consiguieron prácticamente su independencia gracias a este sistema, el mismo no se basaba en el principio de libre determinación de los pueblos, además de referirse exclusivamente a los territorios coloniales -no a minorías étnicas o nacionales- $\mathrm{y}$ de excluir cualquier derecho a la autodeterminación o representación interna. De hecho, durante esta primera fase de la evolución del prin-

deración que las aspiraciones de los gobiernos, cuyo fundamento habrá de ser determinado»; Punto IX «Reajuste de las fronteras italianas de acuerdo con el principio de la nacionalidad»; Punto X: «Oportunidad para un desarrollo autónomo de los pueblos del Imperio Austrohúngaro»; Punto XI: «Evacuación de Rumanía, Serbia y Montenegro, concesión de un acceso al mar a Serbia y arreglo de las relaciones entre los estados balcánicos de acuerdo con sus sentimientos y el principio de nacionalidad»; Punto XII: «Seguridad de desarrollo autónomo de las nacionalidades no turcas del Imperio otomano, y el Estrecho de los Dardanelos libres para toda clase de barcos», y Punto XIII «Declarar a Polonia como un estado independiente, que además tenga acceso al mar». Véase a este respecto RAIC, D., Statehood and the Law of Self-Determination, op. cit., p. 181.

23 Discurso del Presidente Wilson al Congreso, en sesión conjunta, de 11 de febrero de 1918: «[...] peoples and provinces are not to be bartered about from sovereignty to sovereignty as if they were mere chattels and pawns in a game, even the great game, now forever discredited, of the balance of power; [...] all well defined national aspirations shall be accorded the utmost satisfaction that can be accorded them without introducing new or perpetuating old elements of discord and antagonism that would be likely in time to break the peace of Europe and consequently of the world.» (cursiva añadida).

24 Hannum señala que algunos plebiscitos sí se organizaron, pero fueron minoría y no afectaron a los territorios más significativos de la situación de posguerra. Véase a este respecto HaNNUM, H., «Rethinking Self-Determination», op. cit., p. 5. 
cipio de libre determinación, el mismo no adquirió rango jurídico vinculante en Derecho internacional, quedando por tanto como un postulado político. Así lo concluyó una Comisión de juristas de la Sociedad de Naciones, en el caso de las islas Aaland (1920), que habían manifestado su deseo de anexionarse a Suecia, dejando por tanto de ser finlandesas, en los siguientes términos: «Aunque el principio de libre determinación de los pueblos ocupa un lugar importante en el pensamiento político moderno, sobre todo desde la guerra mundial, conviene destacar que no figura recogido en el Pacto de la Sociedad de Naciones. Y la consagración de este principio en cierto número de tratados internacionales no basta para considerarlo como una de las reglas positivas del Derecho de Gentes... El Derecho internacional positivo no reconoce, pues, a colectivos nacionales, como tales, el derecho a separarse por un simple acto de voluntad del Estado del que forman parte» ${ }^{25}$.

\section{SEgunda ETAPa: NACIONES Unidas y La DESCOlONIZACióN}

La adopción de la Carta de las Naciones Unidas en 1945, no supuso, por sí misma, un cambio notable en la evolución del principio de libre determinación. El principio aparece en dos ocasiones en el articulado de la Carta, ambas referencias promovidas por la U.R.S.S. ${ }^{26}$, que sin embargo tenían un carácter programático y no fueron desarrolladas. Así, el artículo 1.2 señala como uno de los propósitos de la nueva organización el de fomentar entre las naciones relaciones de amistad basadas en el respeto al principio [...] de la libre deter-

25 Dictamen consultivo de 5 de septiembre de 1920, Journal Officiel de la Sociedad de Naciones, suplemento especial n ${ }^{\circ} 3$, octubre 1920,5. Véase a este respecto también GUTIÉRREZ ESPADA, C. y Cervell Hortal, M. J., El Derecho Internacional en la encrucijada. Curso General de Derecho Internacional Público, Trotta, Madrid, 2012 [3 $3^{\mathrm{a}}$ ed.], p. 601. No obstante, la Comisión de juristas nombrada por la Sociedad de Naciones adelantó una noción que años más tarde cobraría mucho protagonismo en el desarrollo del principio de libre determinación al concluir que «the separation of a minority from the State of which it forms a part and its incorporation in another State can only be considered as an altogether exceptional solution, a last resort when the State lacks either the will or the power to enact and apply just and effective guarantees». Idem, 28.

26 Brownlie, I., 43.1. Brownlie, «An Essay in the History of the Principle of Self-Determination», Grotius Society Papers, 1968, p. 98 «The fact remains that amendments were proposed jointly by the United States, U.S.S.R., United Kingdom and China on 5 May 1945 which introduced the provisions now embodied as Article 1, paragraph 2, and Article 55 of the Charter. Both amendments referred to relations among nations "based on respect for the principle of equal rights and self-determination of peoples". The amendments were instigated by the U.S.S.R.». 
minación de los pueblos. Asimismo, el artículo 55 dispone, en el marco de la cooperación internacional económica y social, que la nueva organización promoverá una serie de medidas con el «propósito de crear las condiciones de estabilidad y bienestar necesarias para las relaciones pacíficas y amistosas entre las naciones, basadas en el respeto al principio de la igualdad de derechos y al de la libre determinación de los pueblos». Por último, como señaló BROWNLIE, el artículo 76(b) de la Carta, relativo a la administración fiduciaria, si bien no mencionaba el principio, hacía también referencia a «los deseos libremente expresados de los pueblos interesados.»

Tres años más tarde, la Declaración Universal de Derechos Humanos, adoptada y proclamada por la Asamblea General en su resolución 217 A (III), de 10 de diciembre de 1948, no hacía mención al principio de libre determinación. De hecho, tanto la Carta como la Declaración reconocían el hecho colonial, e incluso lo perpetuaban al regular la primera su funcionamiento (arts. 73-91) y solicitar la segunda, respecto de los derechos y libertades en ella reconocidos, su reconocimiento y aplicación universales y efectivos, «tanto entre los pueblos de los Estados Miembros como entre los de los territorios colocados bajo su jurisdicción ${ }^{27}$. Sin embargo, las continuas reclamaciones de los territorios coloniales, junto con el apoyo que a las mismas brindaban relevantes Estados de la nueva organización como la URSS, llevaron a la Asamblea General de la ONU a adoptar la resolución 1514 (XV), de 14 de diciembre de 1960, y su Declaración sobre la concesión de la independencia a los países y pueblos coloniales, en la que se afirma con rotundidad que «Todos los pueblos tienen el derecho de libre determinación; en virtud de este derecho, determinan libremente su condición política y persiguen libremente su desarrollo económico, social y cultural.[Además]En los territorios en fideicomiso y no autónomos y en todos los demás territorios que no han logrado aún su independencia deberán tomarse inmediatamente medidas para traspasar todos los poderes a los pueblos de esos territorios, sin condiciones ni reservas, en conformidad con su voluntad y sus deseos libremente expresados, y sin distinción de raza, credo, ni color, para permitirles gozar de una libertad y una independencia absolutas» ${ }^{28}$.

27 Declaración Universal de Derechos Humanos, adoptada y proclamada por la Asamblea General en su resolución 217 A (III), de 10 de diciembre de 1948, preámbulo.

28 Declaración sobre la concesión de la independencia a los países y pueblos coloniales, aprobada por la resolución 1514 (XV) de la Asamblea General de las Naciones Unidas el 14 de diciembre de 1960, 947a sesión plenaria. 
Esta resolución se refería además a las colonias (territorio no autónomos en términos de la Carta) como territorios que están separados geográficamente del país que los administra y son distintos de éste en sus aspectos étnicos o culturales ${ }^{29}$, doctrina ésta conocida como del agua azul (blue wáter) o agua salada, que requería un espacio marítimo entre el territorio metropolitano y el territorio colonial y que había sido propuesta por los Estados americanos para rechazar que el derecho de libre determinación pudiera ser aplicado a poblaciones aborígenes de Estados ya existentes ${ }^{30}$. De facto, la calificación de territorio colonial la realizaría posteriormente el Comité de la Descolonización que creó la Asamblea General con su resolución 1654 (XVI), de 27 de noviembre de 1961. La resolución 1514 (XV) concluía con una referencia a la necesidad de respetar el principio de integridad territorial, tanto de los Estados ya existentes como de los nuevos Estados que surgieran de la descolonización $^{31}$. Un día después, mediante la resolución 1541 (XV), la Asamblea General de las Naciones Unidas aclaró que el ejercicio del principio de la libre determinación por un pueblo colonial no tenía que conllevar necesariamente la independencia, como se desprendía de la resolución 1514(XV), sino que dicho pueblo podía también optar por la asociación y la integración en un Estado pre-existente, que podía ser el metropolitano u otro ${ }^{32}$.

La concepción del principio como un derecho de los pueblos coloniales a la independencia, asociación o integración, se mantuvo en la resolución 2625(xXV) de la Asamblea General de Naciones Unidas, de 24 de octubre de 1970, que contiene la Declaración relativa a los principios de derecho internacional referentes a las relaciones de amistad y a la cooperación entre los estados de conformidad con la Carta de las Naciones Unidas ${ }^{33}$. Con base en este marco, entre 1945 y

29 Resolución 1541 (XV), principio IV.

30 Véase a este respecto, por ejemplo, Clavero, B., Derecho indígena y cultura constitucional en América, Siglo XXI, México, 1994, p. 62.

31 Declaración sobre la concesión de la independencia a los países y pueblos coloniales, aprobada por la resolución 1514 (xV) de la Asamblea General de las Naciones Unidas el 14 de diciembre de 1960, 947a sesión plenaria, apartados 4, 6 y 7.

32 Resolución 1541 (XV), anexo, principios VII, VIII y IX.

33 En el marco de la aplicación del principio de la igualdad soberana de derechos y de la libre determinación de los pueblos la Declaración relativa a los principios de derecho internacional referentes a las relaciones de amistad y a la cooperación entre los estados de conformidad con la Carta de las Naciones Unidas estipulaba que «El establecimiento de un Estado soberano e independiente, la libre asociación o integración con un Estado independiente o la adquisición de cualquier otra condición política libremente decidida por un pueblo constituyen formas del ejercicio del derecho de libre determinación de ese pueblo.» 
2003, 70 territorios no autónomos según el capítulo XI de la Carta optaron por la independencia, 14 se integraron en otro Estado y 4 eligieron un estatuto de asociación con otro ${ }^{34}$. El principio de libre determinación se convirtió por tanto en el vehículo elegido para llevar a cabo la descolonización ${ }^{35}$.

\section{TERCERA ETAPA: El PRINCIPIO DE LIBRE DETERMINACIÓN Y LOS PUEBLOS NO COLONIALES}

Desde finales de la década de los sesenta del siglo xx, y definitivamente desde los años setenta del pasado siglo, una nueva etapa comienza en la evolución del derecho de libre determinación de los pueblos. Encauzado el proceso descolonizador, y consolidado el derecho de los pueblos coloniales a la libre determinación a nivel incluso de costumbre internacional ${ }^{36}$, la atención de la comunidad internacional relativa a este principio se gira hacia otros pueblos distintos de los coloniales, espoleada por el lenguaje de la Resolución 2625 (xXv) de 1970, que reconocía a todos los pueblos la posibilidad de adquirir, aparte de la independencia, la libre asociación o la integración reconocida por resoluciones anteriores a los pueblos coloniales, «la adquisición de cualquier otra condición política libremente decidida por un pueblo» como una forma del ejercicio del derecho de libre determinación de ese pueblo.

Dos tipos de «pueblos» no coloniales han protagonizado desde entonces el debate en torno al alcance del principio de libre determinación, a saber, los pueblos indígenas y los pueblos nacionales. Respecto de los primeros, en el marco de Naciones Unidas se suele utilizar la definición de pueblo indígena formulada por el Relator Especial de las Naciones Unidas de la Comisión de Derechos Humanos sobre la situación de los derechos humanos y las libertades fundamentales de los indígenas, el ecuatoriano José R. Martínez Cobo, a pesar de que existen otras incluidas en textos jurídicos ${ }^{37}$. Según esta definición

34 Crawford, J., The creation of States, Oxford University Press, Oxford, 2006.

35 Castellino, J., «International Law and Self-determination Peoples, Indigenous Peoples and Minorities», en Walter, C., Ungern-STERnberG, A. y Abushov, K. (eds.), Self-Determination and Secession in International Law, Oxford University Press, Oxford, 2014, p. 30, o Rigo SUREDA, A., The evolution of the right of self-determination: A study of United Nations practice, Sijthoff, Leiden, 1973.

36 Véase por ejemplo a este respecto la Sentencia de la Corte Internacional de Justicia sobre Timor oriental (Portugal c. Australia) de 30 de junio de 1995.

37 Como la definición que da el Convenio relativo a la protección e integración de las poblaciones indígenas y de otras poblaciones tribuales y semitribales en los países independientes: «Pobla- 
«Son comunidades, pueblos y naciones indígenas los que, teniendo una continuidad histórica con las sociedades anteriores a la invasión y precoloniales que se desarrollaron en sus territorios, se consideran distintos de otros sectores de las sociedades que ahora prevalecen en esos territorios o en partes de ellos. Constituyen ahora sectores no dominantes de la sociedad y tienen la determinación de preservar, desarrollar y transmitir a futuras generaciones sus territorios ancestrales y su identidad étnica como base de su existencia continuada como pueblos, de acuerdo con sus propios patrones culturales, sus instituciones sociales y sistemas legales ${ }^{38}$.

El Convenio 169 de lo Organización Internacional del Trabajo de 1989, del que España es parte, reconoce «las aspiraciones de esos pueblos a asumir el control de sus propias instituciones y formas de vida y de su desarrollo económico y a mantener y fortalecer sus identidades, lenguas y religiones [si bien] dentro del marco de los Estados en que viven ${ }^{39}$. Más recientemente, la Declaración sobre los Derechos de los Pueblos Indígenas, aprobada por la Asamblea General de Naciones Unidas el 13 de septiembre de 2007, tras más de 20 años de debates, reconoce el derecho de estos pueblos a la libre determinación, en concreto a determinar libremente su condición política y perseguir libremente su desarrollo económico, social y cultural, conforme a su artículo 3. Sin embargo, la Declaración niega con rotundidad que este derecho pueda menoscabar el principio de integridad territorial de los Estados en los que viven estos pueblos en su artículo $46^{40}$. En el mismo sentido, el Proyecto de Declaración Americana sobre los Derechos de los Pueblos Indígenas, elabora-

ciones tribales o semitribales que habitan en territorios de países independientes contemplados como indígenas por descender directamente de los habitantes que moraban el país o región geográfica a la que pertenece el país en el tiempo de conquista o colonización, y que, independientemente del régimen legal, siguen viviendo más en conformidad con las instituciones sociales, económicas y culturales de sus ancestros que con las actuales del país al que pertenecen». C107 Organización Internacional del Trabajo, Convenio sobre poblaciones indígenas y tribuales, 1957 ( $\mathrm{n}^{\circ}$ 107). (Entrada en vigor: 02 junio 1959).

38 Estudio del Problema de la Discriminación contra las Poblaciones Indígenas, del Relator Especial de la Subcomisión de Prevención de Discriminaciones y Protección a las Minorías (UN Doc. E/CN.4/Sub.2/1986/7/Add.4 (1986)).

39 Párrafo quinto de su Preámbulo (Convenio número 169 de la OIT, hecho en Ginebra el 27 de junio de 1989, y ratificado por España el 29 de enero de 2007, BOE de 8 de marzo).

40 Artículos 46.1: «Nada de lo contenido en la presente Declaración se interpretará en el sentido de que confiere a un Estado, pueblo, grupo o persona derecho alguno a participar en una actividad o realizar un acto contrarios a la Carta de las Naciones Unidas, ni se entenderá en el sentido de que autoriza o alienta acción alguna encaminada a quebrantar o menoscabar, total o parcialmente, la integridad territorial o la unidad política de Estados soberanos e independientes.» 
do en el marco de la Organización de Estados Americanos, estipula que «Los pueblos indígenas tienen derecho a la libre determinación. En virtud de ese derecho determinan libremente su condición política y persiguen libremente su desarrollo económico, social y cultural $\gg^{41}$. El proyecto limita, en su artículo Xx, el ejercicio de la libre determinación de estos pueblos a la autonomía o al autogobierno en las cuestiones relacionadas con sus asuntos internos y locales, así como a disponer de medios para financiar sus funciones autónomas, y excluye explícitamente cualquier afectación con base en el mismo a la integridad territorial de los Estados en su artículo $\mathrm{IV}^{42}$. En suma, la libre determinación de los pueblos indígenas no incluye, como en el caso de los pueblos coloniales, el derecho a la secesión del Estado en el que viven ${ }^{43}$.

Más incierto es el estado de la cuestión respecto de los pueblos nacionales fuera del ámbito colonial. En concreto, en esta tercera etapa se ha planteado si los mismos tienen también derecho a la libre determinación y, en ese caso, si ese derecho es similar al de los pueblos coloniales en el sentido de que puede dar lugar, si así lo desean, a la independencia. Respecto de estas minorías o pueblos nacionales, en el marco de Naciones Unidas se suele utilizar la clásica definición dada en 1977 por Francesco Capotorti, Relator Especial de la Subcomisión de Prevención de Discriminaciones y Protección a las Minorías en el siguiente sentido: «Un grupo numéricamente inferior al resto de la población de un Estado, que se encuentra en una posición no dominante y cuyos miembros, que son nacionales del Estado, poseen características étnicas, religiosas o lingüísticas diferentes de las del resto de la población y manifiestan, aunque sólo sea implícitamente, un sentimiento de solidaridad para preservar su cul-

41 Artículo III del Proyecto, aprobado el 10 de febrero de 2015 - Decimoquinta Reunión de Negociaciones para la Búsqueda de Consensos y el 17 y 18 de mayo de 2016 - Decimonovena Reunión de Negociaciones para la Búsqueda de Consensos.

42 Artículo XX del Proyecto, aprobado el 9 de marzo de 2015 - Decimosexta Reunión de Negociaciones para la Búsqueda de Consensos. El artículo IV, aprobado el 18 de mayo de 2016 - Decimonovena Reunión de Negociaciones para la Búsqueda de Consensos, establece lo siguiente: «Nada de lo contenido en la presente Declaración se interpretará en el sentido de que confiere a un Estado, pueblo, grupo o persona derecho alguno a participar en una actividad o realizar un acto contrarios a la Carta de la Organización de los Estados Americanos y a la Carta de las Naciones Unidas, ni se entenderá en el sentido de que autoriza o alienta acción alguna encaminada a quebrantar o menoscabar, total o parcialmente, la integridad territorial o la unidad política de Estados soberanos e independientes.

43 Véase también a este respecto Gutiérrez Espada, C. y Cervvell Hortal, M. J., El Derecho Internacional en la encrucijada. Curso General de Derecho Internacional Público, op. cit., p. 596 y Torrecuadrada García-Lozano, S., Los pueblos indígenas en el orden internacional, Dykinson, Madrid, 2001. 
tura, sus tradiciones, su religión o su idioma $\gg^{44}$. A nivel regional se suele hacer también referencia a la definición incluida en el artículo 1 de la Resolución 1201 de la Asamblea Parlamentaria del Consejo de Europa de 1 de febrero de $1993^{45}$.

Respecto de estos pueblos, Hannum ha constatado que a partir de la década de los setenta del pasado siglo, en esta tercera etapa de evolución del principio de libre determinación, hay cierta confusión entre los postulados de las dos etapas anteriores, a saber, los relativos a la necesidad de un gobierno democrático y representativo para ejercer el principio que defendía el Presidente Wilson durante la primera etapa, con los del derecho de un pueblo a obtener la independencia del Estado del que forma parte, reconocido a los pueblos coloniales en la segunda etapa descrita en la sección anterior ${ }^{46}$. En efecto, una de las cuestiones más debatidas en el Derecho internacional contemporáneo es la de si los pueblos nacionales pueden, con base en el derecho de libre determinación, acceder a la independencia de los Estados de los que forman parte si así lo expresan de forma democrática.

El punto de partida del debate doctrinal y práctico sobre la autodeterminación de los pueblos nacionales lo constituyen, por un lado, el artículo 1 común del Pacto Internacional de Derechos Civiles y Políticos y del Pacto Internacional de Derechos Económicos, Sociales y Culturales, que señala que «Todos los pueblos tienen el derecho de libre determinación» y, por otro, la Declaración aneja a la resolución 2625 (xxv), en concreto su párrafo séptimo, en el que se incluye la denominada como cláusula de salvaguardia. En primer lugar, en relación con los Pactos, intensas negociaciones tuvieron lugar en la Comisión de Derechos Humanos de Naciones Unidas y en la propia Asamblea General para elaborar un Pacto de derechos civiles, políticos, económicos, sociales y culturales en el que se reconocería como derecho el de libre

44 E/CN.4/Sub.2/384/Rev.1, párr. 568.

45 Resolución 1201 (1993) de la Asamblea Parlamentaria del Consejo de Europa, art. 1: en el siguiente sentido «La expresión 'minoría nacional' se refiere a un grupo de personas dentro de un Estado que: a. residen en el territorio de ese Estado y son sus ciudadanos; b. mantienen vínculos antiguos, firmes y duraderos con ese Estado; c. muestran características distintivas étnicas, culturales, religiosas o lingüísticas; d. son suficientemente representativas, aunque menores en número que el resto de la población de ese Estado o de una región de ese Estado; e. se encuentran motivadas por el deseo de preservar en su conjunto aquello que constituye su identidad común, incluyendo su cultura, sus tradiciones, su religión y su lengua.»

46 Hannum, H., «Rethinking Self-Determination», Virginia Fournal of International Law, op. cit., p. 32. 
determinación. Como es sabido, la distinta entidad que algunos miembros de Naciones Unidas otorgaban a unos derechos (los civiles y políticos) frente a otros (los económicos, sociales y culturales) determinó que se tuvieran que adoptar dos pactos en diciembre de 1966, el Pacto Internacional de Derechos Civiles y Políticos y el Pacto Internacional de Derechos Económicos, Sociales y Culturales, que entraron en vigor en 1976, y que cuentan con más de 110 ratificaciones. No obstante, el primer artículo de ambos Pactos es idéntico, y recoge el derecho de libre determinación en los siguientes términos:

$\ll 1$. Todos los pueblos tienen el derecho de libre determinación. En virtud de este derecho establecen libremente su condición política y proveen asimismo a su desarrollo económico, social y cultural.

2. Para el logro de sus fines, todos los pueblos pueden disponer libremente de sus riquezas y recursos naturales, sin perjuicio de las obligaciones que derivan de la cooperación económica internacional basada en el principio de beneficio recíproco, así como del derecho internacional. En ningún caso podrá privarse a un pueblo de sus propios medios de subsistencia.

3. Los Estados Partes en el presente Pacto, incluso los que tienen la responsabilidad de administrar territorios no autónomos y territorios en fideicomiso, promoverán el ejercicio del derecho de libre determinación, y respetarán este derecho de conformidad con las disposiciones de la Carta de las Naciones Unidas».

La mención en el primer apartado del artículo a «Todos los pueblos» parece hacer referencia a pueblos coloniales y no coloniales, incluidos los nacionales. Sin embargo, del estudio de los trabajos preparatorios, de las votaciones de las distintas comisiones que se encargaron de redactar este artículo, y de los documentos publicados por algunos de los negociadores se desprende que la visión mayoritaria, al menos en el momento de la adopción de los mencionados Pactos -no necesariamente en el momento de su entrada en vigor- era que el derecho de libre determinación iba destinado exclusivamente a los pueblos coloniales, que podrían alcanzar la independencia con base en el mismo ${ }^{47}$.

47 Véase a este respecto la opinión de un alto funcionario de los Estados Unidos de América que participó activamente en las negociaciones: «[a pesar de la amplia formulación del artículo 1 de los pactos el derecho de libre determinación] would be understood in United Nations doctrine as a right belonging only to colonial peoples, which once it had been successfully exercised could not be invoked again, and it would not include a right of secession except for colonies». La cita aparece recogida por HaNnUM, H., «Rethinking Self-Determination», op. cit., p. 5. Véase 
No obstante, la cuestión distaba de ser pacífica, como demostró la reserva que India formuló al artículo 1 de ambos Pactos, mediante la que señalaba que el derecho de libre determinación se refería exclusivamente a los pueblos coloniales, y que fue objetada por los Países Bajos, Alemania y Francia en el sentido de que dicho artículo se refería a todos los pueblos, y por tanto no sólo a los coloniales ${ }^{48}$.

También a nivel regional el principio de libre determinación se ha consolidado como un derecho. Así, el Acta Final de Helsinki, un texto político firmado por 35 Estados europeos en el marco de la Conferencia sobre la Seguridad y la Cooperación en Europa de 1975, señalaba en su Principio VIII que «En virtud del principio de la igualdad de derechos y libre determinación de los pueblos, todos los pueblos tienen siempre el derecho, con plena libertad, a determinar cuándo y cómo lo deseen, su condición política interna y externa, sin injerencia exterior, y a proseguir, como estimen oportuno, su desarrollo político, económico, social y cultural». La lectura de este párrafo, y en particular la referencia a «siempre» y a la condición política «interna y externa» invita a pensar en un alcance mayor para el derecho de libre determinación, despojado ya entonces de su limitación al ámbito colonial. Sin embargo, la lectura de otros principios incluidos en el mismo documento, en concreto el Principio III, relativo a la inviolabilidad de las fronteras ${ }^{49}$, y del Principio IV, de integridad territorial de los Estados ${ }^{50}$, así como de los trabajos preparatorios de este documento y del Documento de Clausura de la reunión de Viena de 1989, que incluía de nuevo el

también Remiro Brotons, A., «Desvertebración del Derecho internacional en la sociedad globalizada», Cursos Euromediterráneos Bancaja de Derecho internacional, vol. V, 2001, p. 110 y GuTIÉRREZ EsPADA, C., «El derecho de libre determinación de los pueblos», op. cit., p. 655.

48 Ibidem.

49 Según este principio «Los Estados participantes consideran mutuamente como inviolables todas sus fronteras, así como las fronteras de todos los Estados en Europa y en consecuencia se abstendrán ahora y en el futuro de atacar dichas fronteras. En consecuencia, se abstendrán también de toda exigencia o de todo acto encaminado a apoderarse y usurpar todo o parte del territorio de cualquier Estado participante.»

50 Según este principio «Los Estados participantes respetarán la integridad territorial de cada uno de los Estados participantes. Por consiguiente, se abstendrán de toda acción incompatible con los propósitos y principios de la Carta de las Naciones Unidas, contra la integridad territorial, la independencia política o la unidad de cualquier Estado participante, y en particular de cualquier acción semejante que constituya una amenaza o uso de la fuerza. Los Estados participantes se abstendrán asimismo de hacer del territorio de cualquiera de ellos objeto de ocupación militar o de otras medidas de fuerza directas o indirectas que contravengan el derecho internacional, u objeto de adquisición mediante tales medidas o la amenaza de ellas. Ninguna de tales ocupación o adquisición se reconocerá como legal.» 
texto del Principio VIII, descartan que el alcance del principio de libre determinación en el marco de Estados ya constituidos fuera del ámbito colonial pueda equivaler a un derecho a la secesión o independencia ${ }^{51}$.

Del mismo modo, la Carta Africana de Derechos Humanos y de los Pueblos, aprobada el 27 de julio de 1981, durante la XVIII Asamblea de Jefes de Estado y Gobierno de la Organización de la Unidad Africana, reunida en Nairobi, Kenia, y que entró en vigor el 21 de octubre de 1986, reconoce también el derecho de libre determinación de todos los pueblos:

«1. Todos los pueblos tendrán derecho a la existencia. Tendrán el incuestionable e inalienable derecho a la autodeterminación. Decidirán libremente su status político y procurarán su desarrollo económico y social según la política que ellos mismos hayan escogido libremente.

2. Los pueblos colonizados u oprimidos tendrán derecho a liberarse de las ataduras de la dominación recurriendo a cualquier medio reconocido por la comunidad internacional.

3. Todos los pueblos tendrán derecho a la ayuda de los Estados firmantes de la presente Carta en su lucha por la liberación de la dominación extranjera, ya sea política, económica o cultural».

Como se ha observado, los Estados que surgieron de la descolonización, la mayor parte de ellos africanos, han mantenido una visión particularmente restrictiva del derecho a la libre determinación desde su independencia, lo que cabe explicar en base a la heterogeneidad de los pueblos y etnias de África, y a la necesidad de reforzar las estructuras de Estado, las fronteras y la integridad territorial de los relativamente recientes Estados africanos ${ }^{52}$. Lo mismo se ha afirmado más recientemente respecto de Estados surgidos de declaraciones unilaterales de independencia realizadas por minorías nacionales ${ }^{53}$.

51 Documento de clausura de la reunión de Viena de 1986 de los representantes de los estados participantes en la Conferencia sobre la Seguridad y la Cooperación en Europa, convocada sobre la base de las disposiciones del acta final relativas a la continuidad de la conferencia, Viena, 1989. Véase a este respecto también CASSESE, A., Self-determination of peoples. A legal reappraisal, op. cit., p. 287.

52 Véase a este respecto, entre otros, Hannum, H., «Rethinking Self-Determination», op. cit., p. 30 que recoge además la siguiente cita del profesor tanzano I. G. SHIVJI: «[E]xisting state practice in Africa... has isolated one element in the principle [of self-determination], the element of anti-colonialism, and absolutised it. It has also raised the derivative elements, state sovereignty and territorial integrity... to the level of the main principle.»

53 Véase en concreto, respecto de la declaración de independencia de Kosovo, que no reconoce el derecho de autodeterminación a las minorías que habitan ese territorio, GUTIÉRREZ ESPA- 
En segundo lugar, la denominada cláusula de salvaguardia incluida en la Resolución 2625(XXV) establece lo siguiente: «Ninguna de las disposiciones de los párrafos precedentes se entenderá en el sentido de que autoriza o fomenta cualquier acción encaminada a quebrantar o menospreciar, total o parcialmente, la integridad territorial de Estados soberanos e independientes que se conduzcan de conformidad con el principio de la igualdad de derechos y de la libre determinación de los pueblos antes descritos y estén, por tanto dotados de un gobierno que represente a la totalidad del pueblo perteneciente al territorio, sin distinción por motivo de raza, credo o color». Posteriormente, la Declaración de Viena de 25 de junio de 1993, aprobada por consenso por representantes de 171 Estados recogía prácticamente el mismo texto ${ }^{54}$, como también haría la resolución 50/6, de 24 de octubre de 1995, adoptada con motivo del cincuentenario de las Naciones Unidas ${ }^{55}$. Esta cláusula fue fruto de un compromiso entre potenciales occidentales como Estados Unidos, que pretendían extender el derecho de libre determinación a todos los pueblos, y los países americanos y africanos, muchos de ellos antiguas colonias, unidos a los socialistas, que se oponían a ello. El texto final, con base en una propuesta italiana y otra libanesa, restringe ese derecho

DA, C. y Bermejo García, R., «Kosovo de nuevo: apuntes críticos sobre su declaración de independencia, su constitución y otras reflexiones», Real Instituto Elcano, documento de trabajo no 41/2008, Madrid, 2008, p. 11.

54 Declaración y Programa de Acción de Viena de la Conferencia Mundial de Derechos Humanos de Naciones Unidas de 25 de junio de 1993 (1993), apartado I.2., «[...] nada de lo anterior se entenderá en el sentido de que autoriza o fomenta acción alguna encaminada a quebrantar o menoscabar, total o parcialmente, la integridad territorial o la unidad política de Estados soberanos e independientes que se conduzcan de conformidad con el principio de la igualdad de derechos y de la libre determinación de los pueblos y estén, por tanto, dotados de un gobierno que represente a la totalidad del pueblo perteneciente al territorio, sin distinción alguna.»

55 Resolución 50/6, de 9 de noviembre de 1995, que incluye la Declaración con motivo del cincuentenario de las Naciones Unidas: «[nos comprometemos a] Seguir reafirmando el derecho de todos los pueblos a la libre determinación, teniendo en cuenta la situación particular de los pueblos sometidos a dominación colonial o a otras formas de dominación u ocupación extranjeras, y reconociendo el derecho de los pueblos a tomar medidas legítimas, de conformidad con la Carta de las Naciones Unidas, encaminadas a realizar su derecho inalienable a la libre determinación. Nada de lo anterior se entenderá en el sentido de que autoriza o fomenta acción alguna encaminada a quebrantar o menoscabar, total o parcialmente, la integridad territorial o la unidad política de Estados soberanos e independientes que se conduzcan de conformidad con el principio de la igualdad de derechos y de la libre determinación de los pueblos y estén, por tanto, dotados de un gobierno que represente a la totalidad del pueblo perteneciente al territorio, sin distinción alguna.» 
a aquellos pueblos que estén sometidos por gobiernos que discriminen por motivos de raza, credo o color ${ }^{56}$.

De la lectura de la cláusula de salvaguardia parece desprenderse que el derecho de libre determinación para los pueblos que no son coloniales exige que los Estados en los que habitan dichos pueblos no les discriminen, ni les persigan por motivos de raza, credo o color. Como se ha afirmado, se trata del derecho de un pueblo a elegir su propio régimen económico y político ${ }^{57}$, pero dentro de las fronteras del Estado del que el pueblo forma parte. No es un derecho, por tanto, a la independencia del Estado del que forma parte sino a participar en la res publica del mismo ${ }^{58}$. A este respecto, como han sostenido Gutierrez Espada y Cervell HorTaL ${ }^{59}$, el artículo 25 del Pacto Internacional de Derechos Civiles y Políticos recogería la esencia, el alma, de la autodeterminación interna. Según este precepto

«Todos los ciudadanos gozarán [...] sin restricciones indebidas, de los siguientes derechos y oportunidades:

a) Participar en la dirección de los asuntos públicos, directamente o por medio de representantes libremente elegidos;

56 Véanse a este respecto, Cassese, A., Self-determination of peoples. A legal reappraisal, op. cit., pp. 109-117; TANCREDI, A., «Secessione e Diritto Internazionale», Rivista di Diritto Internazionale, vol. LXXXI (1998), fasc. 3, p. 690. Véase también entre la doctrina Española PEREA UNCETA, J. A., «El secesionismo catalán en el contexto del derecho internacional», Foro, Nueva época, vol. 17, n 2 (2014), pp. 126-127.

57 CASSESE, C., Self-determination of peoples. A legal reappraisal, op. cit., especialmente p. 101.

58 Véase sobre el principio de libre determinación aplicable a los pueblos nacionales no coloniales, entre otros, Véase también MARIÑo MENÉNDEZ, F., «Naciones Unidas y el derecho de autodeterminación», en MARIÑO MENÉNDEZ, F. (ed.), Balance y perspectivas de naciones Unidas en el cincuentenario de su creación, Univ. Carlos III-BOE, Madrid, 1996, pp. 77-110, especialmente pp. 85-86; Buchanan, A., Secesión, Causas y consecuencias del divorcio político, Ariel, Barcelona, 2013 (edición en español del libro publicado en 1991 con un interesante prólogo sobre la situación de Cataluña), Gutiérrez Espada, C. y Cervell Hortal, M. J., El Derecho Internacional en la encrucijada. Curso General de Derecho Internacional Público, Trotta, Madrid, 2012 [3ª ed.], pp. 596-601; CASSESE, A., Self-determination of peoples. A legal reappraisal, op. cit., especialmente pp. 346-59; SÁENZ DE SANTAMARÍA, P.A., «La libre determinación de los pueblos en la nueva sociedad internacional», en CARDONA LLORENS (coord.) Cursos euromediterráneos Bancaja de Derecho Internacional, Castellón de la Plana, 1997, pp. 113-204, especialmente pp. 152-159; THORNBERRY, P., «The Democratic or Internal Aspect of Self-Determination with Some Remarks on Federalism», en Tomuschat, C. (ed.), Modern Law of Self-Determination, Dordrecht, Nijhoff, 1993, pp. 101-138; o Rosas, A., «Internal Self-Determination», en TOMUSCHAT, C. (ed.), Modern Law of Self-Determination, op. cit., pp. 225-251.

59 Véase a este respecto GutiÉRreZ Espada, C. y Cervell Hortal, M. J., El Derecho Internacional en la encrucijada. Curso General de Derecho Internacional Público, Trotta, Madrid, 2012 [3ª ed.], p. 601. 
b) Votar y ser elegidos en elecciones periódicas, auténticas, realizadas por sufragio universal e igual y por voto secreto que garantice la libre expresión de la voluntad de los electores;

c) Tener acceso, en condiciones generales de igualdad, a las funciones públicas de su país» ${ }^{60}$.

En este contexto, con base en la cláusula de salvaguardia de la Resolución 2625(XXV), si los gobiernos de dichos Estados se comportan de este modo, es decir, si se conducen de conformidad con el principio de libre determinación así entendido, entonces su integridad territorial estará protegida, o, en los términos de la cláusula, «ninguna de las disposiciones de los párrafos precedentes se entenderá en el sentido de que autoriza o fomenta cualquier acción encaminada a quebrantar o menospreciar, total o parcialmente, la integridad territorial de Estados soberanos e independientes». Por el contrario, en caso de que los Estados con minorías nacionales discriminen, persigan u opriman a éstas, cabría entender de la lectura de la cláusula que dejan de estar protegidos por el principio de integridad territorial ${ }^{61}$.

Sin embargo, uno de los principales estudiosos del principio de libre determinación, el profesor y juez Cassese añadía al estudio de los orígenes de la cláusula de salvaguardia que, con independencia de las vicisitudes que sufrió el texto de la misma, se desprendía con claridad de las posturas de los diferentes Estados, y especialmente de la práctica estatal, que la cláusula de salvaguardia no pretendía extender el derecho a la secesión a los pueblos nacionales ${ }^{62}$. Esta opinión se vería reforzada por la propia Resolución 2625(xxv) que añade después de la cláusula de salvaguardia una última frase destinada a reforzar el principio de integridad territorial:

«Todo Estado se abstendrá de cualquier acción dirigida al quebrantamiento parcial o total de la unidad nacional e integridad territorial de cualquier otro Estado o país».

60 Adoptado y abierto a la firma, ratificación y adhesión por la Asamblea General en su Resolución 2200 A (XXI), de 16 de diciembre de 1966, entró en vigor el 23 de marzo de 1976, artículo 25.

61 TANCREDI, A., «Secessione e Diritto Internazionale», op. cit., p. 690.

62 CASSESe, A., Self-determination of peoples. A legal reappraisal, op. cit., en especial en pp. 120-122 «Whatever the intentions of the draftsmen and the result of their negotiations, and whatever the proper interpretation of the clause under discussion, it cannot be denied that State practice and the overwhelming view of States remain opposed to secession. Indeed, it seems that this is one of the few areas on which full agreement exists among all States.» 
En el mismo sentido cabría entender también las famosas palabras del Secretario General de la Organización de las Naciones Unidas, U-THANT, en el año de la adopción de la Resolución 2625(XXV):

«En su calidad de Organización internacional, la ONU no ha aceptado nunca, no acepta y pienso que no aceptará jamás el principio de secesión de una parte de uno de sus Estados miembros» ${ }^{63}$.

Ahora bien, si el derecho a la secesión se excluye, incluso ante discriminaciones notables, persecución u opresión de las minorías nacionales, resulta difícil determinar qué consecuencia conllevaría el incumplimiento del principio de libre determinación por parte de gobiernos que discriminen por motivos de raza, credo o color o, en los términos de la cláusula de salvaguardia en sus dos versiones más recientes, por gobiernos dotados de un gobierno que no represente a la totalidad del pueblo perteneciente al territorio, sin distinción alguna.

Ante esta situación, numerosos autores han concluido que, en casos extremos de discriminación, persecución u opresión de una minoría nacional por parte del gobierno del Estado en el que viven, la cláusula de salvaguardia ampara la secesión de la minoría nacional objeto de la discriminación o persecución ${ }^{64}$. Esta lectura de la cláusula de salvaguardia, conocida como la de secesión como remedio (remedial secession), nos parece, como se ha expuesto anteriormente, que es la que mejor se ajusta al texto de la mencionada cláusu-

63 Conférence de presse su Secretaire Général, ONU. Chronique mensuelle, 7 (1970), nº 2,

64 Véase a este respecto, por ejemplo, CraWford, J., The creation of States, Oxford University Press, Oxford, 2006, p. 119: «At least it is arguable that, in extreme cases of oppression, international allows remedial secession to discrete peoples within a State, and that the «safeguard clauses» in the Friendly Relations and the Vienna Declaration recognize this, even if indirectly.»; TomUSCHAT, C. «Secession and Self-Determination», en KoHEN, M., Secession: International Law Perspectives, Cambridge University Press, Cambridge, 2006), p. 177 «International law, therefore, would recognize 'a continuum of remedies ranging from the protection of individual rights to minority rights, and ending with secession as the ultimate remedy', véase también en relación con la cita Buchieit, L.C., Secession, The Legitimacy of Self-Determination, Yale, New Haven, 1978, p. 222; DoeHring, K., «Self-Determination», en SimMA, B. (ed.), The Charter of the United Nations: A Commentary, Oxford University Press, Oxford, 2nd ed., 2002, p. 58; o the right to unilateral secession 'arises only in the most extreme of cases and, even then, under carefully defined circumstances'. SHAW, M., International Law, Cambridge University Press, Cambridge, $6^{a}$ ed., 2008. «The only arguable exception to this rule that the right to external self-determination applies only to colonial situations (and arguably situations of occupation) might be where the group in question is subject to 'extreme and unremitting persecution' coupled with the 'lack of any reasonable prospect for reasonable challenge' [...]» o GUTIÉRREZ ESPADA, C, «El derecho de libre determinación de los pueblos», op. cit., p. 672: «el Derecho debe ser comprensivo con los pueblos a los que el Estado en el que viven arrinconan y maltratan.» 
la, y así lo sostiene gran parte de la doctrina más autorizada ${ }^{65}$. En este sentido, SOROETA LiCERAS llega a afirmar que la secesión como remedio es, esencialmente, un término sinónimo al de cláusula de salvaguardia ${ }^{66}$.

Esta interpretación, que se desprendía también del Informe de la Comisión de Expertos nombrada por el Consejo de la Sociedad de Naciones en relación con las Islas Aland ${ }^{67}$, ha sido avalada por la conocida sentencia del Tribunal Supremo de Canadá de 28 de agosto de 1998 sobre Quebec. En esta sentencia el Tribunal Supremo canadiense distingue entre libre determinación interna y externa ${ }^{68}$, y señala, tras constatar que el principio de libre determinación ha sido reconocido en documentos que consistentemente subrayaban también la importancia del principio de integridad territorial, que un Estado cuyo gobierno representa a la totalidad del pueblo o pueblos residentes en su territorio, sobre una base de igualdad y sin discriminación, y respetando los principios de la libre determinación en sus propias disposiciones internas, tiene derecho a la protección en virtud del derecho internacional de su integridad territorial ${ }^{69}$. Asimismo, el Tribunal Supremo canadiense admitió, si

65 Véase en este sentido también la posición de DugARD, J. y RAIC, D., «The role of recognition in the law and practice of secession», en KoHen, M., Secession: International Law Perspectives, Cambridge University Press, Cambridge, 2006), pp. 94 y ss.; Ouguergouz, F. y TeHINDRAZANARIVELO, D.L., «The question of secession in Africa», en KoHEN, M., Secession: International Law Perspectives, Cambridge University Press, Cambridge, 2006), pp. 257 y ss.; y THIO, L.A., «International law and secession in the Asia and Pacific regions», en KoHEN, M., Secession: International Law Perspectives, Cambridge University Press, Cambridge, 2006), pp. 297 y ss.

66 Soroeta Liceras, J., «La opinión consultiva de la Corte Internacional de Justicia sobre Kosovo de 22 de julio de 2010: Una interpretación judicial sui generis para un caso que no lo es. Aplicabilidad de la cláusula de salvaguardia de la Resolución 2625 (XXV) o de la "secesión como remedio"», Revista Electrónica de Estudios Internacionales, nº 25 (2013), p. 28.

67 League of Nations 'The Aaland Island Question: Report Submitted to the Council of the League of Nations by the Commission of Rapporteurs 16 April 1921' League of Nations Council Doc B.7 21/68/106, 28: «The separation of a minority from the State of which it forms a part and its incorporation in another State can only be considered as an altogether exceptional solution, a last resort when the State lacks either the will or the power to enact and apply just and effective guarantees.»

68 Tribunal Supremo de Canadá, Reference re Secession of Quebec, [1998] 2 SCR 217, 25506, apartado 126: «The recognized sources of international law establish that the right to self-determination of a people is normally fulfilled through internal self-determination - a people's pursuit of its political, economic, social and cultural development within the framework of an existing state. A right to external self-determination (which in this case potentially takes the form of the assertion of a right to unilateral secession) arises in only the most extreme of cases and, even then, under carefully defined circumstances $[\ldots] \gg$.

69 Id. 130: «There is no necessary incompatibility between the maintenance of the territorial integrity of existing states, including Canada, and the right of a "people" to achieve a full measure of self-determination. A state whose government represents the whole of the people or peoples 
bien con reservas ${ }^{70}$, la posibilidad de que el Derecho internacional acepte la secesión de pueblos no coloniales u oprimidos por una potencia extranjera, es decir de pueblos o minorías nacionales, como ultima ratio, en el caso de que dicha minoría no pueda ejercer su derecho a la libre determinación interna ${ }^{71}$.

El derecho a la libre determinación interna, y la posibilidad de la secesión como último remedio ha sido también reconocida en dos decisiones de la Comisión Africana de Derechos Humanos y de los Pueblos, en concreto en los asuntos Katangese Peoples' Congress c. Zaire y Kevin Mgwanga Gunme c. Camerún ${ }^{72}$. Tomuschat añade que la independencia y posterior reconocimiento de Bangladesh es un ejemplo de secesión como remedio ${ }^{73}$. Sin embargo, otro reconocido sector doctrinal, entre los que se incluye el actual Secretario General del prestigioso Instituto de Derecho Internacional,

resident within its territory, on a basis of equality and without discrimination, and respects the principles of self-determination in its own internal arrangements, is entitled to the protection under international law of its territorial integrity.»

70 Id. Apartado 135: El Tribunal afirmó que resulta «poco claro que esta «tercera propuesta refleje actualmente un estándar bien establecido de Derecho internacional [...]»

71 Id., apartados 134-135: «[...] the underlying proposition is that, when a people is blocked from the meaningful exercise of its right to self-determination internally, it is entitled, as a last resort, to exercise it by secession. The Vienna Declaration requirement that governments represent "the whole people belonging to the territory without distinction of any kind" adds credence to the assertion that such a complete blockage may potentially give rise to a right of secession. [...] Clearly, such a circumstance parallels the other two recognized situations in that the ability of a people to exercise its right to self-determination internally is somehow being totally frustrated. While it remains unclear whether this third proposition actually reflects an established international law standard, it is unnecessary for present purposes to make that determination.»

72 Katangese Peoples' Congress v. Zaire, Comm. No. 75/92 (2000) AHRLR 72 (ACHPR, 1995) (8 Ann. Activity Rep.); Kevin Mgwanga Gunme v. Cameroon, Comm. No. 266/2003, ACHPR, 26 Ann. Activity Rep. (2008-2009). En los términos utilizados por la Comisión en el segundo de los asuntos, con referencia al primero: «It is the view of the Commission, however that, in order for such violations to constitute the basis for the exercise of the right to self-determination under the African Charter, they must meet the test set out in the Katanga case, that is, there must be: «concrete evidence of violations of human rights to the point that the territorial integrity of the State Party should be called to question, coupled with the denial of the people, their right to participate in the government as guaranteed by Article 13.1». Véanse en relación con estos casos ShelTon, D. «Self-Determintaion in Regional Human Rights Law: From Kosovo to Cameroon», 105 AJIL (2011), 67; y Dugard, J., The Secession of States and Their Recognition in the Wake of Kosovo (Hague Academy of International Law), Martinus Nijhoff/Brill, Holanda, 2013 , p. 87-88 y 214.

73 Tomuschat, C., «Seccesion and Self-determination», en Kohen, M. (ed.), Secession International Law Perspectives, Cambridge University Press, Cambridge, 2006, p. 42: «as pointed out, the events leading to the establishment of Bangladesh and the events giving rise to Kosovo as an autonomous entity under international administration can both be classified as coming within the purview of remedial secession.» 
el Profesor KoHen, rechaza que la cláusula de salvaguardia pueda amparar la secesión de pueblos no coloniales. Según estos autores, la cláusula de salvaguardia fue redactada en el contexto de la situación existente en Sudáfrica y Rodesia, y sin pretensión alguna de promover la secesión ni siquiera ante casos de regímenes racistas. Además, la secesión, argumentan, es una solución que conlleva la pérdida de territorio de un Estado de forma permanente, mientras que la discriminación o la persecución pueden haber sido temporales y, por tanto, la solución debería ser la de obligar al gobierno del Estado en cuestión a cesar la violación de los derechos humanos de las minorías o pueblos afectados ${ }^{74}$.

Estos autores se apoyan además en algunos documentos de Naciones Unidas en los que, en efecto, la Organización se muestra contraria a la fragmentación del principio de integridad territorial de los Estados por parte de las minorías nacionales. Por ejemplo, en el Informe del Secretario General de 17 de junio de 1992, titulado: «Un Programa de Paz, Diplomacia preventiva, establecimiento de la paz y mantenimiento de la paz» se afirma con rotundidad que «Las Naciones Unidas no han cerrado sus puertas, pero si cada grupa étnico, religioso o lingüístico pretendiera formar un Estado, la fragmentación no tendría fin, con lo que serían aún más difíciles de alcanzar la paz, la seguridad y el bienestar económico para todos. [...] No puede permitirse que en el período que se avecina dos elementos de gran valor e importancia, a saber la soberanía y la integridad territorial de los Estados dentro del sistema internacional establecido, por una parte, y el principio de libre determinación de los pueblos, por la otra, actúen de manera antagónica.»

74 Castellino, J., International Law and Self-determination, M. Nijhoff, La Haya-Boston-Londres, 2000, p. 40; KoHen, M.G. «L'emploi de la force et la crise de Kosovo: Vers un nouveau désordre juridique international», Révue Belge de Droit International, XXXII, nº 1 (1999), pp. 127-129 y KoHEN, M. G., Secession: International Law Perspectives, Cambridge University Press, Cambridge, 2006), pp. 10-11; CHRISTAKIs, T., «The State as a 'primary fact': some thoughts on the principle of effectiveness», en Kohen, M., Secession: International Law Perspectives, Cambridge University Press, Cambridge, 2006), pp. 138 y ss.; TANCREDI, A., «A normative 'due process' in the creation of States through secession», en KoHen, M., Secession: International Law Perspectives, Cambridge University Press, Cambridge, 2006), pp. 171 y ss.; CoRTEN, O., «A propos d'un désormais 'classique': Le droit à l'autodetermination en dehors des situations de décolonisation, de Théodore Christakis», Révue Belge de Droit International, XXXII (1999), 1, pp. 329-349; y Corten, O., «Are there gaps in the international law of secession?», en KoHEN, M., Secession: International Law Perspectives, Cambridge University Press, Cambridge, 2006), pp. 231 y ss.; Kaczorowska, A., Public International Law, Fourth edition, Routledge, 2010, p. 607, o más recientemente en España MEdina ORTEGa, M., El derecho de secesión en la Unión Europea, Marcial Pons, Madrid, 2014, p. 168. 
En un sentido similar, el Comité para la Eliminación de la Discriminación Racial («CERD» por sus siglas en inglés), órgano de expertos independientes encargado de supervisar la aplicación de la Convención Internacional sobre la Eliminación de todas las Formas de Discriminación Racial concluyó, en su Recomendación General 21, que «el derecho internacional no ha reconocido el derecho general de los pueblos a declarar unilateralmente su secesión de un Estado» ${ }^{75}$. Más recientemente, en un sentido similar, la Misión Internacional Independiente de Investigación del Conflicto de Georgia, encargada por la Unión Europea, concluyó que conforme al derecho internacional el derecho de autodeterminación del que gozan las regiones de Osetia del Sur y Abjasia no equivale a la secesión fuera del contexto colonial ${ }^{76}$. Se trataría, por tanto, de un derecho al ejercicio de la autodeterminación interna ${ }^{77}$. A este respecto, cabe preguntarse si la intención original de la cláusula de salvaguardia, tal y como ha sido interpretada con vigor doctrinal por CASSESE, así como la posición sostenida en los documentos de Naciones Unidas de principios o mediados de los años noventa del pasado siglo no se ha visto superada por la reacción de la comunidad internacional y de la doctrina, e incluso de la propia Corte Internacional de Justicia, ante acontecimientos más recientes, particularmente en relación con la desintegración de Yugoslavia, donde pueblos nacionales han accedido a la independencia y han sido reconocidos como tales por la comunidad internacional, siendo el último de ellos el pueblo de Kosovo, y aún por otros ejemplos más controvertidos en los que la población de parte del territorio de un Estado, en concreto la población que habita el territorio de Crimea en Ucrania, decidió anexionarse a Rusia.

75 Recomendación General XXI del Comité CERD (Sesión 48ª), 23/08/1996 sobre el derecho de libre determinación «El Comité toma nota de que los grupos o minorías étnicos o religiosos hacen referencia frecuente al derecho a la libre determinación como base de un presunto derecho a la secesión. A este respecto el Comité desea expresar las opiniones siguientes [...] El Comité subraya que, de conformidad con la Declaración sobre las relaciones de amistad, ninguna de las medidas que adopte deberá entenderse en el sentido de que autoriza o promueve la realización de acción alguna encaminada a quebrantar, total o parcialmente, la integridad territorial o la unidad política de Estados soberanos e independientes que se comporten de conformidad con el principio de la igualdad de derechos y de la libre determinación de los pueblos, y cuenten con un gobierno que represente a la totalidad del pueblo perteneciente al territorio, sin discriminación por motivos de raza, creencia o color. A juicio del Comité, el derecho internacional no ha reconocido el derecho general de los pueblos a declarar unilateralmente su secesión de un Estado.»

76 Véase el resumen a este respecto del Informe de la Misión Internacional Independiente de Investigación del Conflicto de Georgia, op. cit., vol. I, p. 17.

77 Informe de la Misión Internacional Independiente de Investigación del Conflicto de Georgia, encargado por la Unión Europea bajo la dirección de la embajadora Dña. Heidi Tagliavini, publicado en septiembre de 2009, vol. I, p. 17. 
La cuestión central del debate sobre la libre determinación de los pueblos nacionales en los últimos años ha girado en torno a Kosovo. Como es sabido, Kosovo se declaró independiente de forma unilateral el 17 de febrero de 2008, a pesar la oposición del Estado del que formaba parte, Serbia, y de la resolución 1244 del Consejo de Seguridad de Naciones Unidas de 10 de junio de 1999, en la que se exigía la apertura de un «proceso político dirigido al establecimiento de un acuerdo-marco político interino, que prevea para Kosovo una autonomía considerable, que tenga en cuenta los acuerdos de Rambouillet y el principio de soberanía e integridad territorial de Yugoslavia...».

La Corte Internacional de Justicia se pronunció en 2010 sobre la declaración unilateral de independencia de Kosovo, afirmando que la misma no fue contraria al Derecho internacional. La Corte eludió no obstante pronunciarse sobre las cuestiones de fondo en dicho asunto ${ }^{78}$, lo que ha sido muy criticado por la doctrina nacional e internacional ${ }^{79}$. De hecho la Corte hizo caso omiso de los argumentos formulados por numerosas partes intervinientes, incluido el Reino de España, que afirmaban que la declaración unilateral vulneraba, inter alia, el principio de soberanía e integridad territorial, que dicho principio no podía considerarse inferior jerárquicamente al de libre determinación de los pueblos a la luz de la Resolución 2625 (xxv), que se aplica tanto a las relaciones de un Estado con terceros Estados como en el marco de las relaciones intraestatales, o que en la práctica del Consejo de Seguridad de las Naciones Unidas no se podían encontrar precedentes en los que se hubiera prescindido de dicho

78 Esencialmente «si un pueblo que forma parte, aun estando administrado internacionalmente, de un Estado soberano puede separarse del mismo unilateralmente; y, la otra, si en tales casos es conforme a Derecho o no el reconocimiento de la entidad secesionista». GUTIÉRREZ ESPADA, C. y Cervell Hortal, M. J., El Derecho Internacional en la encrucijada. Curso General de Derecho Internacional Público, Trotta, Madrid, 2012 [3 $3^{\mathrm{a}}$ ed.], p. 600.

79 Adecuación al Derecho internacional de la Declaración Unilateral de Independencia en Kosovo de 22 de julio de 2010, ICJ Reports 2010. Véase sobre esta opinión, entre otros, DUGARD, J., The Secession of States and Their Recognition in the Wake of Kosovo (Hague Academy of International Law), op. cit.; HiLPOLD, P. (ed.), Kosovo and International Law The ICf Advisory Opinion of 22 fuly 2010, Brill, Leiden, 2012; y, entre nosotros, e.g. GutiÉRrEZ EsPaDA, C. y BERMEJo GarCÍa, R., «De la Opinión consultiva de la Corte Internacional de Justicia, de 22 de julio de 2010, sobre Kosovo», Documento de Trabajo 35/2010, 10/11/2010, 1-13; BERMEjo GarCía, R. y GuTIÉRREZ EsPADA, C. «La declaración unilateral de independencia de Kosovo a la luz de la opinión consultiva de la Corte Internacional de Justicia de 22 de julio de 2010 y de las declaraciones, opiniones individuales y disidentes a la misma», Anuario español de Derecho Internacional, vol. 26, 2010, pp. 7-59; Esposito, C., «El discreto ejercicio de la función consultiva de la corte internacional de justicia en el asunto Kosovo», REDI, vol. LXIII (2011), 1 o LópeZ-Jurado Romero DE LA CrUZ, C., «La secesión de territorios no coloniales y el soberanismo catalán», op. cit. 
derecho, y de hecho que en el caso de Kosovo esto era especialmente patente con base en la Resolución $1244(1999)^{80}$. En todo caso, desde su declaración de independencia, más de 100 Estados han reconocido a Kosovo como Estado, siendo los Estados Unidos de América uno de los primeros. Además, varias organizaciones internacionales han aceptado a Kosovo como miembro. Así, el Fondo Monetario Internacional y el Banco Mundial lo hicieron en 2009, el Banco Europeo de Reconstrucción y Desarrollo lo hizo en 2012, y el Banco de Desarrollo del Consejo de Europea lo hizo en 2013. Por otro lado, Kosovo ha sido admitido como miembro por la Comisión de Venecia del Consejo de Europa y por el Comité Olímpico Internacional en 2014.

Los partidarios del reconocimiento de Kosovo como Estado suelen subrayar que se trata de un caso de secesión como remedio debido a la persecución que el pueblo kosovar sufrió por parte del régimen de Milosevic, y único, debido a la intervención armada de la OTAN y a la administración internacional del territorio por varios años, por lo que no debe ser considerado como un precedente para otros pueblos nacionales ${ }^{81}$. En el mismo sentido se pronunciaba antes de la declaración de independencia el Enviado Especial del Secretario General de Naciones Unidas, Marthi Ahtisaari cuando defendía la independencia de Kosovo afirmando que «Kosovo es un caso especial que requiere una solución especial [y que] no crea un precedente para otros conflictos sin resolver ${ }^{82}$. En el mismo sentido, el Consejo de Asuntos Generales

80 Los convincentes argumentos del Reino de España pueden consultarse en el Written Statement of the Kingdom of Spain, de abril de 2009. Puede descargarse de la página web de la Corte Internacional de Justicia en el siguiente enlace <www.icj-cij.org/docket/index.php?p1=3\&p2= $1 \& \mathrm{k}=21 \&$ case $=141 \& \operatorname{code}=\mathrm{kos} \& \mathrm{p} 3=1>$. Un resumen de los argumentos principales relativos a los principios de integridad territorial y libre determinación de los pueblos, elaborado por la directora del equipo que preparó la representación de España y representante ante la Corte en dicho asunto, puede consultarse en Escobar HernáNDEZ, C., «La posición del Reino de España en el procedimiento consultivo: una aproximación general», REDI, $\mathrm{n}^{\circ} 1$ (2011), pp. 11-27, especialmente en pp. 16-21.

81 Véanse, por ejemplo, a este respecto las declaraciones de la Secretaria de Estado de Estados Unidos Condoleezza Rice al anunciar el reconocimiento de Kosovo como Estado soberano e independiente por parte de Estados Unidos: «The unusual combination of factors found in the Kosovo situation -including the context of Yugoslavia's breakup, the history of ethnic cleansing and crimes against civilians in Kosovo, and the extended period of UN administration- are not found elsewhere and therefore make Kosovo a special case. Kosovo cannot be seen as a precedent for any other situation in the world today». El discurso puede consultarse en el siguiente enlace: http://2001-2009.state.gov/secretary/rm/2008/02/100973.htm

82 Informe del Enviado Especial del Secretario General sobre el estatuto futuro de Kosovo. Recomendación: El estatuto de Kosovo debe ser la independencia, supervisada por la comunidad internacional, 5 (párrafo 15) (S/2007/168, 26 de marzo de 2007). 
y Relaciones Exteriores de la Unión Europea, en su sesión de 18 de febrero de 2008, tras recordar su adhesión a los principios de la Carta de las Naciones Unidas y del Acta final de Helsinki, incluidos el principio de integridad territorial y todas las resoluciones del Consejo de Seguridad, consideraron la declaración unilateral de independencia de Kosovo como un caso sui generis que no debía ser interpretado como un precedente para otros casos ${ }^{83}$. Esta posición común no permitió obviamente ocultar el profundo desacuerdo entre la mayoría de Estados Miembros de la UE, partidarios de la independencia de Kosovo, y la minoría representada por países como España y Chipre frontalmente opuestos a dicha independencia ${ }^{84}$. Sin embargo, como adelantaba el Juez Koroma en su opinión disidente ${ }^{85}$, a pesar de todas estas declaraciones, el dictamen de la Corte en el asunto de Kosovo es percibido sin duda como un precedente por aquellos pueblos no coloniales que pretenden la independencia del Estado del que forman parte, y para los Estados que los apoyan. Lo anterior se puso de manifiesto el 26 de agosto de 2008 cuando Rusia reconoció como Estados independientes a los territorios georgianos de Abjasia y Osetia del Sur pese a la oposición de Georgia. En el anuncio de la firma de los decretos presidenciales por los que se reconocía la independencia de las

83 Conclusiones del Consejo de Asuntos Generales y Relaciones Exteriores, Sesión 2851 del Consejo, de 18 de febrero de 2008: «El Consejo reitera la adhesión de la UE a los principios de la Carta de las Naciones Unidas y del Acta final de Helsinki, incluidos el principio de la integridad territorial y todas las Resoluciones del Consejo de Seguridad de las Naciones Unidas. El Consejo subraya su convicción de que ante el conflicto de la década de los años noventa, y el prolongado periodo de administración internacional con arreglo a la RCSNU 1244 , Kosovo constituye un caso sui generis que no pone en tela de juicio estos principios y resoluciones.». Sobre la reacción de la UE a la declaración de independencia de Kosovo véanse, entre otros, TzIFakis, N, «The European Union in Kosovo Reflecting on the Credibility and Efficiency Deficit», Problems of Post-Communism, vol. 60, no. 1 (January-February 2013), pp. 43-54, especialmente en pp. 45-46 y Hughes, J, «Paying for Peace: Comparing the EU's Role in the Conflicts in Northern Ireland and Kosovo», Ethnopolitics, vol. 8, $\mathrm{n}^{\text {os }} 3-4$ (2009), pp. 287-306, especialmente en pp. 297-302.

84 Sobre los argumentos esgrimidos por los estados que han reconocido a Kosovo véase BoLTON, G. y VISOKA, G, «Recognizing Kosovo's independence: Remedial secession or earned sovereignty?», South East European Studies at Oxford, Occasional Paper No. 11/10, 2010.

85 Opinión disidente, Juez Koroma, parr. 4, el Juez hablaba de un precedente muy peligroso: «To accept otherwise, to allow any ethnic, linguistic or religious group to declare independence and break away from the territory of the State of which it forms part, outside the context of decolonization, creates a very dangerous precedent. Indeed, it amounts to nothing less than announcing to any and all dissident groups around the world that they are free to circumvent international law simply by acting in a certain way and crafting a unilateral declaration of independence, using certain terms.» 
dos regiones separatistas, el presidente ruso Medvedev mencionó el asunto de Kosovo como precedente ${ }^{86}$, y con base en éste justificó su decisión en un artículo publicado en el diario Financial Times al día siguiente ${ }^{87}$. A este respecto, como ha sostenido DUGARD, es improbable que Rusia hubiera intervenido de la forma en que lo hizo en el conflicto georgiano, y que hubiera reconocido la independencia de Abjasia y Osetia del Sur en ausencia del precedente de Kosovo $^{88}$. Asimismo, el caso de Kosovo habría obrado también como precedente para la anexión de Crimea por parte de Rusia ${ }^{89}$, claramente contraria al Derecho internacional por vulnerar, inter alia, la integridad territorial de Ucrania $^{90}$. Así lo reconoció el Presidente ruso Vladimir PUTIN al afirmar que Kosovo fue un precedente porque «la situación es completamente la misma que Crimea». Putin añadió también que Occidente sostuvo en el caso de Kosovo que «no hacían falta las autoridades centrales para reconocer a un estado como soberano» y la ONU y la Corte Internacional de Justicia se mostraron de acuerdo. «Presionaron a todos para que reconocieran a Kosovo y ahora se indignan, ¿por qué?» ${ }^{91}$. Como concluyó DugaRD en su Curso de la Academia de la Haya, el reconocimiento de Kosovo por más de 100 Estados, incluyendo a Francia, Reino Unido, Estados Unidos o Alemania ha hecho que Kosovo sea percibido como un precedente para otras minorías y pueblos nacionales ${ }^{92}$.

$86 \mathrm{El}$ anuncio puede consultarse en el siguiente enlace del gobierno ruso <http://archive.kremlin. $\mathrm{ru} / \mathrm{eng} / \mathrm{speeches} / 2008 / 08 / 26 / 1543$ type82912_205752.shtml>.

$87 \mathrm{El}$ artículo del Presidente Medvedev puede aun consultarse en el siguiente enlace: <www.ft.com/ cms/s/0/9c7ad792-7395-11dd-8a66-0000779fd18c.html\#axzz3MKMGANh1>.

88 Dugard, J., The Secession of States and Their Recognition in the Wake of Kosovo (Hague Academy of International Law), Martinus Nijhoff/Brill, Holanda, 2013, p. 199-200. Véase también GHAZARYAN, N., «The ENP and the Southern Caucasus: Meeting the Expectations?», en WHITman, R. G. y WolfF, S. (eds.), The European Neighbourhood Policy in Perspective Context, Implementation and Impact, op. cit., p. 228, quien añade que la promesa de la OTAN de incluir a Georgia y Ucrania como miembros fue el desencadenante definitivo de la reacción rusa para «manipular» la región.

89 Bermejo García, R., «De Kosovo a Crimea: la revancha rusa», Revista Española de Derecho Internacional, 66, $\mathrm{n}^{\circ} 2$ (2014), pp. 307-312.

90 Véase a este respecto, por ejemplo, la reacción de la Unión Europea negándose a reconocer la anexión de Crimea por parte de Rusia al tiempo que ha impuesto sucesivas sanciones a este país y a las autoridades de Crimea por vulnerar el Derecho internacional. La Unión Europea prorrogó las sanciones el pasado 15 de septiembre de 2016.

91 Las declaraciones de PUTIN pueden consultarse en el siguiente enlace a la noticia de Europapress, publicada el 18/03/2014, <www.europapress.es/internacional/noticia-putin-defiendecrimea-siempre-sido-rusa-equipara-caso-kosovo-20140318140316.html>.

92 Dugard, J., The Secession of States and Their Recognition in the Wake of Kosovo (Hague Academy of International Law), Martinus Nijhoff/Brill, Holanda, 2013, p. 199. 
Este autor también señaló que el dictamen de la Corte, y no sólo los reconocimientos, también debe ser considerado como un precedente, al menos en relación con las siguientes afirmaciones realizadas por la Corte, a saber, que una declaración unilateral de independencia que no viola una norma de ius cogens no es contraria al Derecho internacional, que el Derecho internacional prohíbe declaraciones unilaterales de independencia que violan normas de ius cogens, que el principio de integridad territorial se limita a la esfera de las relaciones entre Estados, y que una minoría en un territorio, en el presente caso los albano-kosovares, puede constituir un «pueblo» a los efectos del Derecho internaciona $\mathrm{l}^{93}$.

En suma, durante la tercera fase de evolución, el derecho de libre determinación se extiende a los pueblos indígenas y nacionales. En el caso de los primeros, se reconoce el derecho de estos pueblos a determinar libremente su condición política y perseguir libremente su desarrollo económico, social y cultural pero dentro de las fronteras del Estado en el que viven. En el caso de los pueblos nacionales que viven en un Estado soberano, «si bien pendiente queda aún la concreción última del principio [a ellos aplicable]» ${ }^{94}$, cabe afirmar que se les reconoce el derecho de autodeterminación interna, es decir, a no ser discriminados ni perseguidos y a participar en la gestión de la res publica, por contraposición a la autodeterminación externa de los pueblos coloniales $\mathrm{u}$ ocupados que equivale a la independencia de éstos ${ }^{95}$. Por otro lado, durante esta etapa, la corriente doctrinal que consideraba la posibilidad de una secesión para los pueblos nacionales como último remedio en caso de ser discriminados o perseguidos por parte del gobierno del Estado en el que viven se ha visto reforzada por la independencia de Bangladesh primero, y por el masivo reconocimiento de Kosovo como Estado independiente después, así como por los posicionamientos del Tribunal Supremo de Canadá y de la Comisión Africana de Derechos Humanos y de los Pueblos.

93 Id., p. 200-201.

94 GutiÉRREZ EsPaDA, C, «El derecho de libre determinación de los pueblos», op. cit., p. 679.

95 CanÇado Trindade, A. A., International Law for Humankind Towards a New fus Gentium, Martinus Nijhoff Publishers, Leiden-Boston, 2010, p. 83: «Recent developments in contemporary International Law disclose the dimensions both external and internal of the right of self-determination of peoples: the former means the right of every people to be free from any form of foreign domination, and the latter refers to the right of every people to choose their destiny and to affirm their own will, if necessary against their own government.» 


\section{V. ¿HACIA UNA CUARTA ETAPA BASADA EN EL DERECHO DEMOCRÁTICO DE LOS PUEBLOS NACIONALES A LA INDEPENDENCIA?}

El 27 de septiembre de 2012 el Parlamento de Cataluña adoptó la Resolución 742/IX en la que «proclama solemnemente, tal como ya ha hecho en otras ocasiones trascendentales, el derecho imprescriptible e inalienable de Cataluña a la autodeterminación, como expresión democrática de su soberanía como nación ${ }^{96}$. Posteriormente, el 23 de enero de 2013, el Parlamento de Cataluña aprobó la Resolución 5/X, bajo el título «Declaración de soberanía y del derecho a decidir del pueblo de Cataluña», y cuyo primer apartado afirmaba que «[E]l pueblo de Cataluña tiene, por razones de legitimidad democrática, carácter de sujeto político y jurídico soberano $\gg^{97}$. Más recientemente, la Resolución 1/XI sobre el inicio del proceso político en Cataluña como consecuencia de los resultados electorales del 27 de septiembre de 2015, afirma, en su apartado segundo «El Parlamento de Cataluña declara solemnemente el inicio del proceso de creación de un estado catalán independiente en forma de república» ${ }^{98}$.

El interrogante que plantean estas resoluciones de una institución pública como el Parlamento de Cataluña, a los efectos del presente estudio, es si el Derecho internacional, y en concreto el de libre determinación, podría amparar, en una cuarta fase de su evolución, la secesión unilateral de pueblos nacionales si así lo decide democráticamente su población, en este caso representada por el Parlamento de Cataluña, en ausencia de discriminación o persecución en el sentido de la cláusula de salvaguardia de la Resolución 2625(XXV). A este respecto, si bien la población de Cataluña puede ser considerada como una minoría nacional a los efectos de la Resolución 1201 de la Asamblea Parlamentaria del Consejo de Europa de 1 de febrero de 1993 mencionada anteriormente $^{99}, \mathrm{y}$, como hemos visto, el Dictamen de la Corte Internacional de Justicia en el asunto de Kosovo avalaría que las minorías nacionales puedan ser

96 Resolución 742/IX del Parlamento de Cataluña, de 27 de septiembre de 2012, Párrafo 3 del apartado relativo al denominado derecho a decidir.

97 Resolución 5/X del Parlamento de Cataluña, de 23 de enero de 2013, apartado primero.

98 Resolución 1/XI del Parlamento de Cataluña, sobre el inicio del proceso político en Cataluña como consecuencia de los resultados electorales del 27 de septiembre de 2015, apartado segundo. Otra resolución de 6 de octubre de 2016 convoca un referendum unilateral de independencia para antes de finales de septiembre de 2017

99 Véase en este sentido PerEa UnCETA, J.A., «El secesionismo catalán en el contexto del derecho internacional», op. cit., p. 142. 
consideradas como pueblos a los efectos del derecho de libre determinación, el Derecho internacional actual reconocería el derecho de libre determinación interna al pueblo catalán, derecho que en nuestra opinión ya ejerce, pero no el derecho a la autodeterminación externa o a la secesión unilateral.

Lo anterior obedece a que el Estado español se conduce conforme al principio de libre determinación en el sentido de la Resolución 2625(XXV), pues no puede afirmarse que la población catalana esté discriminada, excluida del gobierno o de la administración pública o, menos aún, perseguida u oprimida, y esto hace que la integridad territorial del Estado español esté protegida por lo dispuesto cláusula de salvaguardia de la Resolución 2625(xXV) así como por otros textos como el Acta Final de Helsinki y en la Declaración de Viena.

Esta opinión es ampliamente compartida por la doctrina, que señala que el denominado «derecho a decidir» al que se hace referencia con frecuencia desde ámbitos políticos de Cataluña no existe en Derecho internacional. Estos autores distinguen también, acertadamente en mi opinión, el contexto que dio lugar al reconocimiento de Kosovo por parte de una gran parte de la comunidad internacional y al Dictamen de la Corte Internacional de Justicia en ese asunto, y concluyen por tanto que una declaración unilateral de independencia por parte de Cataluña no estaría amparada por el Derecho internacional ${ }^{100}$.

Más recientemente, el Secretario General de Naciones Unidas, Ban Kimoon ha recordado, en relación con la situación en Cataluña y el derecho de libre determinación, que España es un estado soberano y que Naciones Unidas respeta la integridad territorial y la soberanía de los estados, añadiendo que, en su opinión, Cataluña no es un territorio sin autogobierno a los que sea

${ }^{100}$ En este sentido destaca el detallado análisis de Pons Rafols, F.X., «Legalidad internacional y derecho a decidir», Revista electrónica de estudios internacionales, ${ }^{\circ} 27$ (2014) y especialmente Cataluña: Derecho a decidir y Derecho internacional, Reus, Madrid, 2015. En el mismo sentido véase MARTín y PÉREZ DE NANClaRes, J., «Reflexiones jurídicas a propósito de una eventual declaración unilateral de independencia de Cataluña: un escenario político jurídicamente inviable», Real Instituto Elcano, 2015; CARRILlO SALCEDO, J.A. «Sobre el pretendido 'derecho a decidir' en el Derecho Internacional contemporáneo», El Cronista del Estado Social y Democrático de Derecho, no 33 (enero de 2013), pp. 20-22, PEREA UnCETA, J.A., «El secesionismo catalán en el contexto del derecho internacional», op. cit.; LóPEZ-Jurado Romero DE La Cruz, C., «La secesión de territorios no coloniales y el soberanismo catalán», op. cit.; MEDINA ORTEGA, M., El derecho de secesión en la Unión Europea, Ed. Marcial Pons, Madrid, 2014; o Buchanan, S., Secesión, Ariel, Barcelona, 2013. Este último autor considera precipitado el derecho a decidir defendido por los partidarios de la secesión en Cataluña, si bien considera que el Estado español debería renegociar la autonomía de Cataluña pues, de lo contrario, se incrementarían los argumentos a favor de un derecho a la secesión no consensuada. 
de aplicación el derecho de libre determinación ${ }^{101}$. Por otro lado, la mencionada Resolución 1/XI del Parlamento de Cataluña sobre el inicio del proceso político en Cataluña como consecuencia de los resultados electorales del 27 de septiembre de 2015, afirma, en su apartado sexto, que «El Parlamento de Cataluña, como depositario de la soberanía y como expresión del poder constituyente, reitera que esta cámara y el proceso de desconexión democrática del Estado español no se supeditarán a las decisiones de las instituciones del Estado español, en particular del Tribunal Constitucional, que considera falto de legitimidad y de competencia a raíz de la sentencia de junio de 2010 sobre el Estatuto de autonomía de Cataluña, votado previamente por el pueblo en referéndum, entre otras sentencias» ${ }^{102}$. A este respecto, conviene precisar que la ignorancia de las resoluciones del Tribunal Constitucional no estaría avalada por legalidad internacional. En este sentido cabe citar la reciente opinión de la Comisión de Venecia relativa a las reformas adoptadas por el Parlamento Polaco a la Ley reguladora del Tribunal Constitucional de Polonia. En esta opinión, y con referencias a su práctica anterior, la Comisión de Venecia concluye que una mayoría parlamentaria no debe ignorar las resoluciones del Tribunal Constitucional, pues lo anterior vulnera el Estado de Derecho, y puede poner en peligro la democracia y los derechos humanos conforme a estándares nacionales, europeos e internacionales ${ }^{103}$.

En suma, a tenor del contenido del derecho de libre determinación aplicable a los pueblos nacionales descrito en las secciones anteriores, y de la postura adoptada por la doctrina internacionalista que ha estudiado el pretendido derecho a la secesión unilateral de Cataluña con arreglo a Derecho internacional, cabe concluir que en el momento presente el derecho a la libre determinación de los pueblos en su dimensión aplicable a los pueblos nacionales como Cataluña no ampararía una secesión no consensuada de este territorio con el Estado español.

101 Véase a este respecto la entrevista concedida a cuatro medios el 30 de octubre de 2015. La entrevista puede consultarse en el siguiente enlace <www.elmundo.es/espana/2015/10/30/5633b1 $4 \mathrm{cca} 4741 \mathrm{~b} 21 \mathrm{~d} 8 \mathrm{~b} 4614 . \mathrm{html}>$.

102 Resolución 1/XI del Parlamento de Cataluña, sobre el inicio del proceso político en Cataluña como consecuencia de los resultados electorales del 27 de septiembre de 2015, apartado sexto.

103 Opinion no. 833/2015, European Commission for Democracy through Law (Venice Commission), Venecia, 11 de marzo de 2016. Véase por ejemplo el apartado 143: «Not only the Polish Constitution but also European and international standards require that the judgments of a Constitutional Court be respected.» 


\section{Conclusiones}

A la luz de las consideraciones anteriores, podemos deducir las siguientes conclusiones. En primer lugar, durante la primera fase de evolución del principio de libre determinación, es decir, desde 1916 y hasta la creación de las Naciones Unidas, a pesar de las referencias al mismo como un derecho, tanto por parte de Lenin como de Wilson, y antes otros como Stalin, el principio no adquirió rango jurídico en Derecho internacional, quedando por tanto relegado a la categoría de postulado político o idea-fuerza, utilizada además de forma estratégica y sesgada en función de los intereses de las distintas potencias. Este postulado político inicial resultó, sin embargo, determinante para las siguientes etapas de evolución del principio, debido en especial, al empeño que algunos actores, como la U.R.S.S. pusieron en incorporar el principio a la Carta de Naciones Unidas.

En segundo lugar, tras la creación de la Organización de las Naciones Unidas, y en concreto en la década de los 60 del siglo $\mathrm{xx}$, el principio de libre determinación experimenta una transformación fundamental, a saber, la de su conversión en un derecho reconocido por el ordenamiento jurídico internacional, tanto por resoluciones de la Asamblea General, en las que se aceptaba la secesión de las colonias con base en el mismo, como por los Pactos internacionales firmados en 1966, que desarrollaban la dimensión democrática del mismo. Se trataba, no obstante, de un derecho limitado al ámbito colonial, no desplegando efectos jurídicos fuera del mismo. Con base en este marco, la mayoría de territorios no autónomos según el capítulo XI de la Carta alcanzaron la independencia, y otros optaron por la asociación con el Estado que habitaban.

En tercer lugar, a partir de 1970, con la Resolución 2625(xxv) de la Asamblea General y la entrada en vigor de los Pactos Internacionales de derechos humanos en 1976, el derecho de libre determinación se extiende a los pueblos indígenas y nacionales. En el caso de los primeros, diversos instrumentos internacionales reconocen el derecho de estos pueblos a determinar libremente su condición política y a perseguir libremente su desarrollo económico, social y cultural pero dentro de las fronteras del Estado en el que viven, es decir, excluyendo de su alcance la independencia o secesión unilateral. Por otro lado, en el caso de los pueblos nacionales que viven en un Estado soberano, con base en la cláusula de salvaguardia de la Resolución 2625(XXV) y la interpretación de «todos los pueblos» que se hace a partir de este momento de los Pactos Internacionales, se reconoce el derecho de estos pueblos a no ser discriminados 
ni perseguidos y a participar en la gestión de la res publica. Además, durante esta etapa, una corriente doctrinal muy numerosa -que este autor suscribeha aceptado la posibilidad de que los pueblos nacionales puedan acceder a la secesión no consensuada como último remedio en caso de ser discriminados o perseguidos por parte del gobierno del Estado en el que viven, tesis que ha sido apoyada en los últimos años por diversas resoluciones de instituciones nacionales e internacionales.

En cuarto lugar, el derecho a la libre determinación de los pueblos, en su dimensión aplicable a los pueblos nacionales como Cataluña, no ampara secesiones no consensuadas basadas exclusivamente en el deseo de independencia manifestado de forma pacífica y democrática por una minoría o pueblo nacional, en ausencia de discriminación o persecución previa por parte del Estado en el que habita dicha minoría en el sentido de la cláusula de salvaguardia de la Resolución 2625(XXV).

Por último, casi 50 años después de la adopción de la Resolución 2625(xxv), $\mathrm{y}$ a sabiendas de que se trata de una propuesta de lege ferenda con escasos visos de ver la luz, sería quizá conveniente que la Asamblea General se volviera a pronunciar sobre el principio de libre determinación de los pueblos en un contexto ahora sí claramente post-colonial, clarificando en concreto su contenido en relación con los pueblos nacionales, y posiblemente también respecto de los pueblos indígenas. Lo anterior podría llevarse a cabo, de forma similar a como propuso Crawford en 1996 respecto del reconocimiento de Estados ${ }^{104}$, a través de una declaración preparada por la Comisión de Derecho Internacional que precisara en qué situaciones y bajo qué premisas un pueblo nacional podría considerarse discriminado o excluido en el sentido de las Resoluciones 2625(XXV) de 1970 y 50/6 de 1995, y qué consecuencias tendría dicha situación, es decir, si como sugiere parte de la doctrina, la comunidad internacional debería obligar al Estado que discrimina o excluye a dejar de hacerlo o, como sugiere otra parte de la doctrina y este autor suscribe, si ante ciertos casos extremos de discriminación o persecución cabría la secesión no consensuada.

104 Crawford, J., The creation of States, Oxford University Press, Oxford, 2006, pp. 757-759. En aquel momento el hoy Juez de la Corte Internacional de Justicia propuso, respecto de la secesión de Estados, a declaratory instrument (not in treaty form) setting out the intrinsic factors relevant to the decision whether an entity qualifies to be treated as a State, and eventually, a full member of the international community, and having full regard to modern State practice. Such an instrument might take the form of a General Assembly Resolution, or alternatively the Assembly might take note of the Commission's own conclusion in the matter.» 
Además, y para reducir el riesgo que para el principio de integridad territorial podría conllevar una declaración como la propuesta, sería conveniente que el Consejo de Seguridad tuviera que pronunciarse sobre el cumplimento por parte de un pueblo nacional de los requisitos mencionados, habida cuenta especialmente de que el Consejo de Seguridad tendrá que pronunciarse eventualmente sobre la admisibilidad del nuevo Estado surgido de la secesión no consensuada en la Organización de las Naciones Unidas conforme al artículo 4.2 de la Carta.

Una resolución de este tipo no parece en la actualidad probable a tenor, inter alia, de la reciente Declaración conjunta de la Federación Rusa y la República Popular China sobre la promoción del Derecho internacional, de 25 de junio de $2016^{105}$, en la que resulta muy llamativo que ambas potencias, al mencionar los principios básicos del Derecho internacional, no hagan referencia explícitamente al de libre determinación, como sí hacen respecto de otros como el de la igualdad soberana, si bien mencionan genéricamente los principios incluidos en la Resolución 2625 (xxv), entre los que está el de libre determinación de los pueblos. De hecho, ambas potencias afirman que se guiarán también por los conocidos Cinco Principios de Coexistencia Pacífica formulados por China, India y Myanmar en 1954, entre los que no figura el de libre determinación de los pueblos, pero sí «el respeto a la soberanía e integridad territorial de cada país» ${ }^{106}$.

${ }^{105}$ La Declaración puede consultarse en inglés en la página web del Ministerio de Asuntos Exteriores de la Federación Rusa: <www.mid.ru/en/foreign_policy/news/-/asset_publisher/cKNonkJE02Bw/content/id/2331698>.

${ }^{106}$ Los cinco principios son: respeto mutuo por la soberanía y la integridad territorial, la no agresión mutua, la no interferencia en los asuntos internos de otros países, igualdad y beneficio mutuo, y la coexistencia pacífica. 
